D.O.I.: $10.3895 /$ gi.v10i3.1853

\title{
PONTO DE RESSUPRIMENTO PARA MATERIAIS COM DEMANDA SAZONAL E ALEATÓRIA: O CASO DE UMA EMPRESA DE GRANDE PORTE
}

\section{RESUPPLY MATERIALS POINT FOR SEASONAL AND RANDOM DEMAND: A CASE STUDY IN A LARGE COMPANY}

\author{
Bárbara Batista Póvoa ${ }^{1}$; Gisele de Lorena Diniz Chaves ${ }^{1}$ \\ ${ }^{1}$ Universidade Federal do Espírito Santo - UFES - São Mateus - Brasil \\ barbara_povoa@hotmail.com \\ ${ }^{2}$ Universidade Federal do Espírito Santo - UFES - São Mateus - Brasil \\ giselechaves@ceunes.ufes.br
}

\begin{abstract}
Resumo
Os estoques são importantes devido a sua função de equilibrar a diferença entre a taxa de fornecimento e a demanda, além de absorver parte significativa do orçamento de qualquer organização. Dentre os diversos tipos de estoques, o de itens MRO - Manutenção, Reparo e Operações - envolve materiais críticos, que podem ter alto custo de estoque, mas que sua ausência impacta fortemente o desempenho financeiro da empresa, visto que pode ser essencial para determinado processo ou operação, além de possuir caráter sazonal. Portanto, o objetivo deste estudo é verificar a eficiência das técnicas de determinação de pontos de ressuprimento de estoque para a reposição de itens $M R O$ por meio de um estudo de caso. A curva ABC e classificação XYZ foram utilizadas para classificar os diferentes materiais em estoque para que os esforços sejam direcionados aos itens mais significativos. Os resultados evidenciam que políticas de ressuprimento diferentes podem ser adotadas de acordo com as necessidades levantadas visando ganhos em excelência operacional. Espera-se que este estudo possa dar suporte à tomada de decisão na gestão de estoque de itens MRO, considerando a complexidade e peculiaridade deste grupo de material.
\end{abstract}

Palavras-chave: gestão de estoques; itens MRO; ponto de ressuprimento.

\section{Introdução}

A gestão de materiais vem ganhando cada vez mais espaço nas discussões do meio acadêmico e corporativo. Isso acontece, devido ao fato de que esta operação absorve parte significativa do orçamento de qualquer organização. De acordo com Betts et al (2008), o estoque permite às operações tirarem vantagens das oportunidades em curto prazo. Algumas oportunidades circunstanciais podem surgir e ocasionar um acúmulo de estoque, mesmo quando não exista uma demanda imediata para ele. No entanto, em caso de excesso de estoque, o armazém pode ter problemas de espaço além de aumentar consideravelmente o valor do capital imobilizado. Pelo lado 
do suprimento, a falta de algum material pode acarretar um prejuízo tão expressivo, que é mais interessante, pagar e manter certo nível de estoque.

Com isso, as empresas que desejam se manter competitivas e atuantes, devem buscar o desenvolvimento da capacidade de coordenar o fluxo de utilização de recursos materiais face ao sistema produtivo e aos níveis de estoque que se tem. De acordo com Ballou (2006), decidir quanto, quando e onde comprar os materiais, deve ser uma preocupação constante. Assim, uma boa gestão deve planejar e controlar essas decisões de programação com outras atividades e interesses dentro da organização, principalmente com a área de Programação e Planejamento da Produção - PCP.

Desta forma, cria-se um trade off importante para os gestores dentro das organizações. Até que ponto é seguro e necessário manter um estoque dentro da empresa? Até que ponto essa alternativa é viável? Estes questionamentos são constantes e a resposta pode variar de acordo com os processos e particularidades de cada setor e de cada organização.

Dentre os diversos tipos de estoques, de produtos acabados ou semiacabados, de matérias primas para o processo produtivo e MRO - Manutenção, Reparo e Operações, este último necessita de atenção especial devido à sua complexidade e peculiaridade e será o alvo do presente estudo. Este grupo de materiais é composto, basicamente, por peças de reposição de equipamentos, manutenção e operação de instalações, materiais de escritório e consumo e constitui parte significativa do estoque geral de grandes indústrias de transformação.

Wanke (2005) afirma que uma típica empresa fabricante de bens de consumo tende a manter entre US\$ 5 a 15 milhões imobilizados em peças de manutenção e reposição, a um custo de oportunidade anual que oscila entre $20 \%$ e $40 \%$ do valor em estoque. Embora a função deste tipo de material seja bem compreendida pelos gerentes de manutenção e suprimentos, muitas empresas enfrentam o desafio de evitar grandes estoques de peças com custos excessivos de manutenção e obsolescência (PORRAS e DEKKER, 2008). Portanto, o desafio em questão é determinar o ponto de ressuprimento que equilibre o custo com o estoque e o nível de estoque que minimize o risco da falta de itens essenciais à manutenção, principalmente quando ocorrem paradas não programadas, ou seja, custo da ruptura de estoque.

A indústria nacional de papel e celulose tornou-se bastante competitiva mundialmente, fato que pode ser explicado pela quantidade e qualidade dos recursos naturais disponíveis, além de ter ainda desenvolvido modernas tecnologias de equipamentos e processos a fim de acompanhar as constantes mudanças de mercado e a necessidade de atender às exigências cada vez maiores de seus clientes. No entanto, este tipo de indústria é conhecido por sua dependência de elevados níveis de estoques de peças de manutenção, reparo e operações, pois os equipamentos da unidade industrial podem sofrer com o desgaste, a corrosão, ou mesmo apresentarem problemas de funcionamento ao 
longo de sua vida útil, exigindo um trabalho de manutenção ou até mesmo a substituição de algumas peças para a retomada das atividades produtivas.

Além disso, é preciso ressaltar que a sazonalidade está presente na demanda por este tipo de material, já que existe um aumento de consumo considerável em paradas programadas para a realização de manutenções diversas. Outro fator também presente neste tipo de estoque é a aleatoriedade, já que a sua utilização nem sempre é programada ou até mesmo esperada pelos clientes. Essa situação impacta diretamente nos níveis de estoque, pois da mesma maneira que se podem passar longos períodos sem a utilização de algum item específico, existe a possibilidade de uma elevada demanda por tal material, e este deve estar disponível em estoque. Além disso, alguns itens do estoque são solicitados apenas no período da realização de manutenção preventiva.

Dentro deste contexto, o objetivo geral deste artigo é verificar a eficiência das técnicas de determinação de pontos de ressuprimento de estoque para a reposição de itens MRO, já que este tipo de abordagem tende a ser mais escasso (BOTTER e FORTUIN, 2000), bem como seus principais conceitos, dificuldades e oportunidades, considerando a particularidade e complexidade da demanda sazonal e aleatória por estes materiais e ainda aplicar as metodologias de Classificação $\mathrm{ABC}$ e XYZ.

\section{Revisão de literatura}

\subsection{Definição de estoque}

Segundo Slack et al (2009), o estoque pode ser definido como a acumulação armazenada de recursos materiais em um sistema de transformação, ou seja, é qualquer recurso que pertence a uma organização, que por algum motivo, está armazenado.

De acordo com Corrêa e Corrêa (2008), existem quatro razões para o surgimento e manutenção dos estoques:

- Falta de coordenação entre fases de um determinado processo;

- Incerteza de previsões de suprimento ou da demanda;

- Especulação para criação de valor e realização de lucro;

- Disponibilidade do canal de distribuição.

Dessa forma, o controle dos estoques deve ser feito juntamente com a administração dos transportes (modais, infraestrutura, distância e custos), o levantamento do tipo de demanda (permanente, sazonal, irregular ou derivada) e ainda do estudo dos espaços físicos disponíveis (armazéns, depósitos e almoxarifados). 


\subsection{Tipos de estoque}

Corrêa e Corrêa (2008) classificam os estoques pela existência de vários tipos identificados nos processos de operações; estoques de matérias-primas e componentes comprados, estoques de material em processo, estoques de produtos acabados e estoques de materiais para MRO.

- Estoques de matérias-primas e componentes comprados: são as quantidades de itens adquiridos pela organização na expectativa de transformá-los, mais ainda não o fez. Ou seja, são insumos que serão trabalhados dentro de uma cadeia de operações para a fabricação de um produto final deste processo.

- Estoques de material em processo: quantidade de itens adquiridos que já sofreram algum tipo de transformação, porém não se encontram prontos para a venda, encontram-se no estágio de semiacabado.

- Estoques de produtos acabados: é o estoque do resultado final da produção, representado pela quantidade de itens de produto acabado pronto para comercialização.

- Estoques de materiais para MRO (manutenção, reparo e operação): são quantidades de itens adquiridos pela operação, com intuito de apoiar a atividade de produção. Ou seja, são aqueles materiais que não são destinados à produção diretamente, embora alguns podem ser imprescindíveis ao processo de fabricação.

Assim, é possível notar que existem diferentes tipos de estoque dentro de uma organização, de forma centralizada em um almoxarifado, como é o caso das matérias-primas e itens de MRO, ou distribuído em vários pontos dentro da empresa, como os estoques de materiais em processo, estoques de ciclo e de antecipação. Estes últimos citados, geralmente, são oriundos de um descompasso da produção, diferença de ritmo entre as operações ou variações da demanda, logo precisam ser minimizados sempre que possível.

Segundo Kennedy, Patterson e Fredendall (2002) os estoques de peças de reposição tem como função básica fazer com que a equipe de manutenção consiga manter os equipamentos em condição de funcionamento e produzindo. Wanke (2005) classifica as peças de reposição em duas categorias: itens reparáveis e itens consumíveis ou descartáveis. Os primeiros são aqueles que são viáveis de recuperação nos aspectos técnicos e econômicos, ou seja, quando há necessidade de recuperação do material, são enviados para oficinas especializadas de maneira a permitir a reutilização do material. Após o reparo, são retornadas para os estoques, estando disponíveis para o uso. A segunda categoria de itens consumíveis ou descartáveis, segundo o autor, é composta apenas por itens novos, que não podem ser recuperados. 
Para Silva (2009) a demanda para peças de reposição tem características bastante peculiares e muito diferentes das que são encontrados normalmente nos produtos, matérias-primas e insumos para a produção. Enquanto os últimos apresentam um padrão de demanda de alto giro, regular e mais previsível, as peças de reposição possuem um padrão de demanda de baixo giro, errático e intermitente, caracterizado por demandas não frequentes, de tamanho variável, ocorrendo em intervalos irregulares.

Este comportamento identificado nos itens MRO deve-se ao fato de haver consumo esporádico e eventos independentes, que podem ser influenciados pelos planos de manutenções preventivas e corretivas, entre outras operações, assim, uma comparação entre os estoques de produtos acabados com os MRO, pode ser visto na Figura 1.

Figura 1 - Comportamento do estoque de Produtos Acabados X Comportamento de estoque MRO

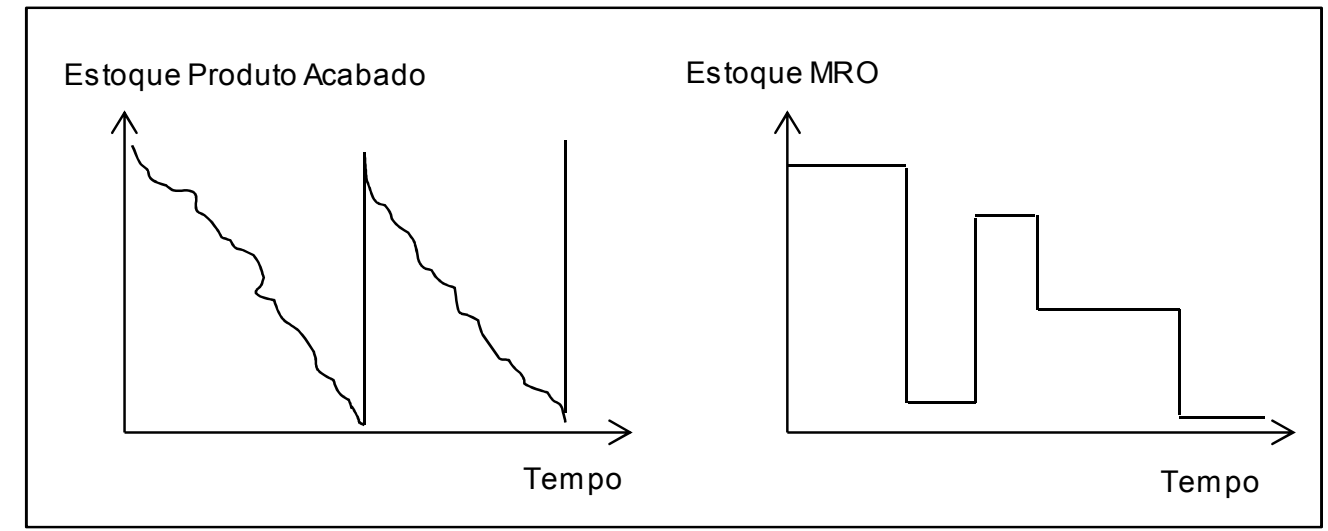

Fonte: Lara e Rodrigues (2012, p.83)

Saggioro, Martin e Lara (2008) analisam a complexidade de gerir estoques de peças de reposição, onde constataram a presença de algumas características particulares, tais como a criticidade para a operação (alto custo de ruptura), pouca oferta de fornecedores qualificados, alto tempo de reposição, imprevisibilidade da demanda, baixo giro de estoques, entre outros. Lara e Rodrigues (2012) afirmam que são essas características que aumentam a complexidade dos cálculos para a melhor definição dos níveis de estoque ideais, dado que as abordagens usuais apresentam uma baixa aderência às situações reais e tendem a colocar mais estoque do que o necessário ou excedendo.

Desta forma, é possível perceber as diferenças existentes entre os tipos de estoques, bem como as peculiaridades e dificuldades dos itens MRO frente aos demais estoques dentro de uma empresa (estoque de matéria prima, produto em processo ou ainda produto acabado).

\subsection{Gestão de estoque}

Segundo Vendrame (2008), a gestão de estoque consiste no ato de gerir recursos ociosos possuidores de valor econômico e destinado ao suprimento das necessidades futuras de material, 
numa organização. Ou seja, são itens mantidos em disponibilidade constante e renovados, permanentemente, para a realização das atividades e consequentemente, produzir lucros e serviços.

A decisão de estocar ou não um determinado produto dependerá muito de sua particularidade quanto a sua complexidade ou facilidade de aquisição. Os estoques absorvem capital que poderia ser investido de outras maneiras, desviam fundos de outros usos potenciais e tem o mesmo custo de capital que qualquer outro projeto de investimento da empresa. Aumentar a rotatividade do estoque libera ativo e economiza o custo de manutenção do inventário. Assim se faz necessário ter uma política de estoque adequada, de tal forma que não se tenha material em excesso e nem em falta (NOGUEIRA, 2012).

De acordo com Francischini (2002), giro ou rotatividade de estoque é definido como número de vezes em que o estoque é totalmente renovado em um período de tempo, geralmente anual. Ou seja, quanto maior o giro, melhor será o resultado da empresa, pois alto giro implica em melhor utilização do capital investido. Esse giro pode ser calculado pela Equação 1:

$$
\text { Girodoestoque }=\frac{\text { DemandaMśdianoperodo }}{\text { EstoqueMsdionoperiodo }} \times 100 \%
$$

Se por um lado, baixos níveis de estoque podem levar a perdas de economias de escala e altos custos de falta, por outro lado o excesso de estoques representa custos operacionais e de oportunidade do capital empatado. Dimensionar os parâmetros de estoque com base neste trade off não é uma tarefa simples, tendo em vista as diversas incertezas e restrições do ambiente logístico (SAGGIORO; MARTIN; LARA, 2008).

\subsection{Custos do estoque}

Um fator de grande relevância e que interfere diretamente na decisão dos gestores em estocar ou não são os custos envolvidos. De acordo com Slack et al (2009), estes custos podem se dividir em:

Custo de colocação de pedido: toda vez que um pedido é colocado para reabastecer o estoque, é necessário transações que representam custo para a empresa.

- Custos de desconto de preços: Muitos fornecedores oferecem descontos sobre o preço normal de compra para grandes quantidades, também podem impor custos extras para pequenos pedidos.

- Custo de falta de estoque: Se houver erro nas quantidades de pedido e gerando a falta de estoque, haverá custos incorridos pela empresa, na realização de um novo pedido e principalmente pela falha no fornecimento aos consumidores. Se os consumidores forem externos, 
poderão trocar de fornecedor; se internos, a falta de estoque pode levar a tempo ocioso no processo seguinte, ineficiências e, eventualmente, outra vez consumidores externos insatisfeitos.

- Custo de capital de giro: quando se coloca um pedido de reabastecimento, para os fornecedores, eles vão demandar pagamento de seus produtos. Quando se fornecem para os próprios clientes, vai-se, por sua vez demandar recebimentos. Por, todavia, haverá provavelmente um intervalo de tempo entre pagar os fornecedores e receber dos clientes. Durante esse tempo, a empresa tem que ter fundos para manter os estoques. Os custos associados são os juros que são pagos ao banco por empréstimos, ou custos de oportunidade de não investir em outros lugares.

- Custo de armazenagem: São os custos associados à armazenagem física dos bens, locação, iluminação e climatização do armazém, juntamente com seguro.

- Custos de obsolescência: Quando se escolhe uma política de pedidos que envolvem a solicitação de quantidades muito grandes, o que significará que os itens estocados permanecerão longos tempos armazenados incorre o risco de que esses itens possam se tornar obsoletos, ou deteriorar-se, juntamente com a perda por danificação.

Todos esses custos precisam ser analisados e minimizados sempre que possível dentro da empresa. No entanto, outro fator precisa ser ressaltado ao se tratar de gestão de estoques, que é a segurança da informação dentro das empresas. Cassarro (2001) afirma que é consenso que as informações no mundo atual são valiosas, e tornam as empresas mais dinâmicas, mais competitivas, a medida que vão possuindo bons sistemas de informação, com pessoas capacitadas e treinadas para utilizá-los.

\subsection{Decisões da gestão de estoque}

Além da decisão de estocar ou não um determinado produto e da busca constante do equilíbrio entre nível de estoque ideal e redução de custos de manutenção desses estoques, existem outras decisões importantes a serem tomadas pela gestão da empresa.

Segundo Slack et al (2009), em cada ponto no sistema de estoque, os gerentes de produção precisam gerir as tarefas do cotidiano dos sistemas. Pedidos de itens de estoque serão recebidos dos consumidores internos e externos; os itens serão despachados e a demanda vai gradualmente consumir o estoque. Serão necessárias colocações de pedidos para reposição de estoques, entregas vão chegar e requerer armazenamento. No gerenciamento do sistema, os gerentes de produção estão envolvidos em três principais tipos de decisões:

- Quanto pedir. Cada vez que um pedido de reabastecimento e colocado, de que tamanho ele deve ser? 
- Quando pedir. Em que momento, ou em que nível de estoque o pedido de reabastecimento deveria ser colocado?

- Como controlar o sistema. Que procedimentos e rotinas devem ser implantados para ajudar a tomar essas decisões? Diferentes prioridades deveriam ser atribuídas a diferentes itens do estoque? Como a informação sobre estoque deveria ser armazenada?

Garcia et al (2006) destaca ainda outras duas decisões importantes em relação à gestão de estoques:

- Com que frequência revisar os níveis de estoque: os níveis de estoque podem ser revisados continuamente ou periodicamente dependendo da tecnologia presente e dos custos de revisão, dentre outros fatores;

- Onde localizar os estoques: se uma empresa pode estocar seus produtos em mais de uma instalação, decisões de localização devem ser tomadas, como por exemplo, manter produtos acabados em armazéns pequenos próximos aos clientes ou em um armazém central, o que depende dos custos de distribuição, restrições de serviço, tempo em que os clientes aceitam esperar, tempo de distribuição, custos de estoque, custos de instalações etc.

Assim, o grande desafio na gestão de estoques de estoque consiste em determinar o que comprar ou produzir, quando realizar um pedido e em quais as quantidades. Visando sempre a redução de custos e mantendo um nível de serviço adequado.

\subsection{Ponto de ressuprimento}

Para Pozo (2010), o ponto de ressuprimento é aquele onde a quantidade de peças que se tem em estoque garante que o processo produtivo não sofra problemas de continuidade enquanto aguarda-se a chegada do lote de compra, durante o tempo de reposição. Isso quer dizer que quando um determinado item de estoque atinge seu ponto de pedido deve-se fazer o ressuprimento de seu estoque, colocando-se um pedido de compra. Para o cálculo do ponto de reposição utiliza-se a Equação 2:

$$
P R=\left(C x T_{R}\right)+E_{S}
$$

Onde,

$P R=$ Ponto de Ressuprimento;

$C=$ Consumo normal da peça;

$T_{R}=$ Tempo de Reposição;

$E_{S}=$ Estoque de Segurança. 
Segundo Garcia et al (2006), um aspecto importante é a divisão entre políticas de revisão continua e revisão periódica. Políticas de revisão contínua são aquelas em que decisões de ressuprimento podem ser tomadas a qualquer instante de tempo, o que é possibilitado pelo monitoramento contínuo de mudanças nos níveis de estoque. Já nas políticas de revisão periódica decisões de ressuprimento só podem ser realizadas em intervalo de tempos predefinidos. Ainda segundo o autor, as políticas de revisão contínua resultam em menores níveis de estoque (em razão de menores estoques de segurança) com o mesmo nível de serviço quando comparadas às políticas de revisão periódica. Entretanto, políticas de revisão periódica, permitem a programação de operações como compras, transporte e recebimentos, o que pode trazer oportunidade de economias de escala e racionalização do uso de recursos. Além disso, revisar os estoques periodicamente pode reduzir os custos de monitoramento e controle.

\subsection{Políticas de revisão contínua}

\subsubsection{Política (s,Q) - Ponto de pedido, quantidade de pedido}

De acordo com Garcia et al (2006), uma das políticas de revisão contínua mais popular é a $(\mathrm{s}, \mathrm{Q})$. Nesta política, uma quantidade Q é pedida toda vez que a posição de estoque atinge um nível de $\mathrm{S}$ unidades, chegando o pedido após lead time de ressuprimento L (TERSINE, 1988; TUBINO, 2000; GARCIA et al, 2006).

Nesta política, a demanda e o lead time são variáveis aleatórias, o que leva a diferentes modelos e decisões. Na Figura 2 é ilustrado o gráfico dente de serra com incertezas na demanda e no lead time.

Figura 2 - Gráfico dente de serra

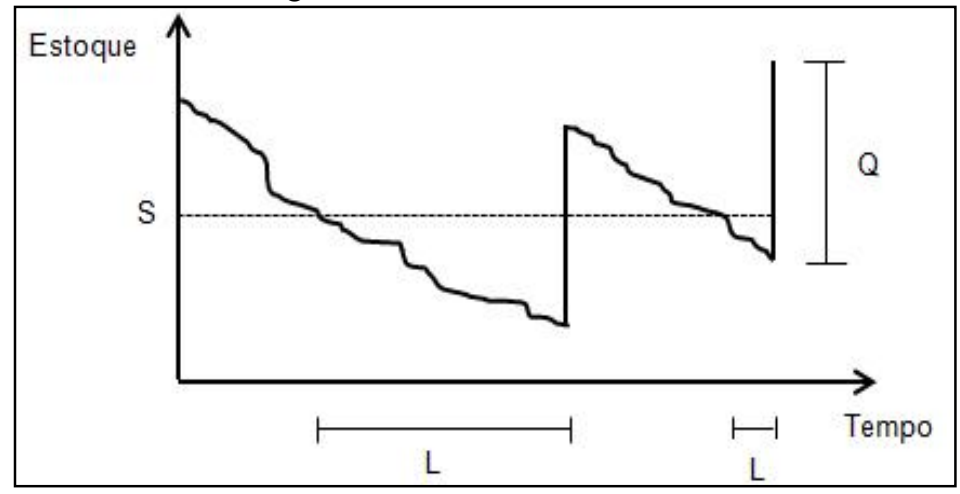

Fonte: Garcia et al, (2006, p.60)

Nessa política, é utilizada a posição de estoque e não o estoque líquido para disparar um pedido. A razão é o fato de a posição de estoque incluir os pedidos de materiais que ainda não foram entregues pelo fornecedor.

De acordo com Tadeu (2010), dentre as vantagens do sistema (s,Q) está a simplicidade de utilização, particularmente para o atendente de almoxarifado, erros são menos prováveis de ocorrer 
e os requerimentos da produção ou manutenção para o fornecedor são previsíveis. A desvantagem principal desta política é que, na forma pura, ela pode não ser capaz de cobrir as demandas individuais muito grandes; em particular, se uma transação que dispara o ressuprimento é grande o suficiente, então o ressuprimento de tamanho Q não elevará a posição do estoque acima do ponto de ressuprimento. Para evitar este problema, deve-se adotar o sistema (s, nQ) onde se disparam os pedidos com quantidades iguais a múltiplos de Q para elevar a posição de estoque acima de s.

\subsubsection{Política (s,S) - Ponto de pedido, estoque máximo}

A política $(\mathrm{s}, \mathrm{S})$ é uma política de revisão contínua (assim como a anterior), também conhecida como min-max. Toda vez que a posição de estoque atinge o ponto de pedido s ou um nível inferior, um pedido é colocado para elevar a posição de estoque para S unidades (LOPES; SANTOS, 2006; TADEU, 2010).

De acordo com Tadeu (2010), se todas as transações de atendimento às demandas dos clientes são unitárias, esta política é idêntica à $(\mathrm{s}, \mathrm{Q})$, sendo Q sempre igual a $\mathrm{S}$ menos s. Entretanto, caso ocorram transações com quantidades maiores que uma unidade do item (demandas dos clientes em lotes), a posição de estoque pode cair abaixo do ponto do pedido, sendo os pedidos de ressuprimento variáveis.

Os pontos de pedido no sistema $(\mathrm{s}, \mathrm{S})$ devem levar em conta a incerteza no tamanho das transações, o que torna mais complexa a derivação de fórmulas analíticas. Em muitos casos, não existe diferença substancial nos níveis de serviço e custos se as características das transações não são levadas em conta. Em outras situações, entretanto, pode ser relevante calcular os valores ótimos exatos para s e S (LOPES e SANTOS, 2006).

\subsection{Políticas de revisão periódica}

\subsubsection{Política (R,S) - Período de revisão, estoque máximo}

De acordo com Garcia et al (2006), o sistema (R,S) é uma das políticas de revisão periódica mais usadas. Neste, a cada $\mathrm{R}$ unidades de tempo (período de revisão) os níveis de estoque são revistos e um pedido é colocado para aumentar a posição de estoque para o nível de $\mathrm{S}$ unidades, como mostra a Figura 3. 
Figura 3 - Gráfico dente de serra para a política $(\mathrm{R}, \mathrm{S})$

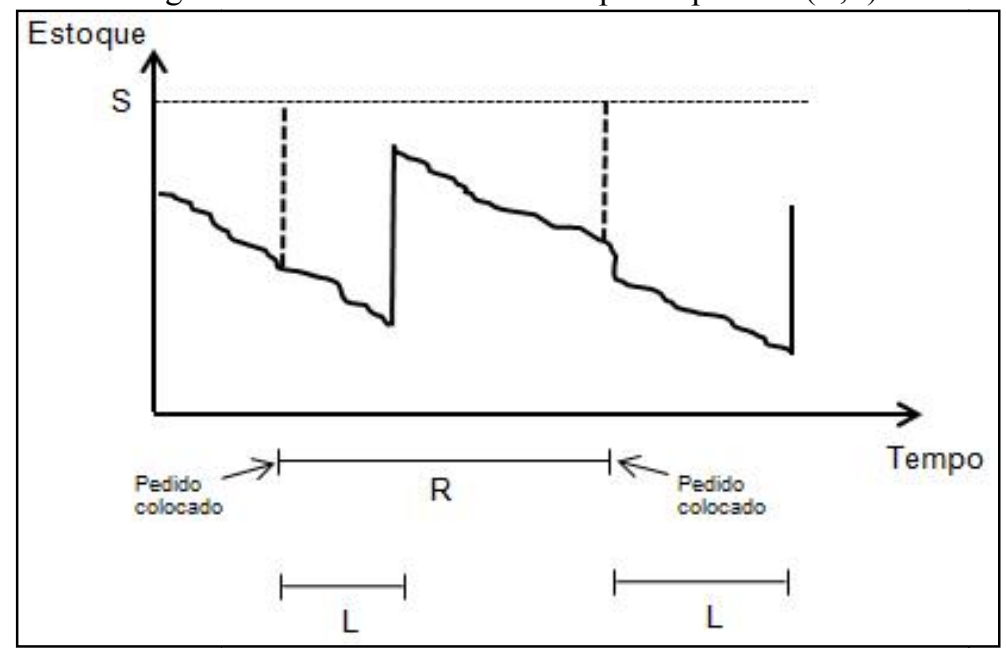

Fonte: Garcia et al, (2006, p.60)

Segundo Tadeu (2010), nenhum pedido pode ser feito entre dois intervalos de revisão. A revisão periódica permite a redução de custos de controle de estoques, especialmente em ambientes pouco informatizados.

Tendo em vista que R é um parâmetro fixo, a colocação de pedidos é programada no tempo, ou seja, sabe-se com certeza que um pedido será feito após um tempo pré-determinado.

Entretanto, o tamanho dos pedidos (ou lotes de ressuprimento) não é constante, sendo calculado por $\mathrm{Q}=\mathrm{S}-\mathrm{I}$. Onde, I é a posição de estoque no momento em que o pedido é realizado. Visto que a demanda total em um intervalo $\mathrm{R}$ é incerta, I não é conhecido até o momento de colocação do pedido (GARCIA et al, 2006; TADEU, 2010).

\subsubsection{Política (R,s,S) - Período de revisão, ponto de pedido, estoque máximo}

Tadeu (2010) afirma que quando a colocação de um pedido tem custo alto, pode ser mais vantajoso não gerar um pedido em todo período de revisão, com objetivo de reduzir os custos do pedido.

A política $(\mathrm{R}, \mathrm{s}, \mathrm{S})$ é uma política de revisão periódica que combina os sistemas anteriores $(\mathrm{R}, \mathrm{S})$ e $(\mathrm{s}, \mathrm{S})$. Os níveis de estoque são revisados a cada $\mathrm{R}$ unidades de tempo. Se a posição de estoque estiver igual ou abaixo do ponto de pedido s no momento da revisão, um pedido é colocado para elevar a posição de estoque para $\mathrm{S}$ unidades. Se em um instante de revisão a posição de estoque estiver acima de $\mathrm{s}$, nenhum pedido é feito. A política $(\mathrm{R}, \mathrm{S})$ pode ser vista como um caso especial da $(\mathrm{R}, \mathrm{s}, \mathrm{S})$, na qual s é igual a $\mathrm{S}$ menos 1.

Para Lopes e Santos (2006), a determinação de valores ótimos para R, s e S no sistema $(\mathrm{R}, \mathrm{s}, \mathrm{S})$ não é simples. Métodos simplificados são normalmente utilizados para encontrar valores aproximados para estes parâmetros, assim como, modelos de simulação também são bastante úteis. 


\subsection{Sistemas de controle e análise de estoques}

\subsubsection{Classificação ABC}

De acordo com Koch (2000), Pinto (2002) e Slack et al (2009), a ferramenta Curva ABC, também conhecida como Princípio 80/20, Princípio de Pareto, Lei de Pareto, Regra 80/20, Princípio do menor esforço e Princípio do desequilíbrio surgiu em 1897, criação de um economista italiano chamado Vilfredo Pareto (1848-1923). Vilfredo criou essa ferramenta para analisar os padrões de riqueza e renda na Inglaterra em meados do século XIX, onde foi constatado que maior parte da renda e da riqueza ia para uma minoria das pessoas em suas amostras, ou seja, a grande parte do dinheiro ficava nas mãos da minoria e pouco dinheiro nas mãos de grande parte da população. Como resultado, Pareto descobre a existência de uma relação matemática que relaciona a proporção de pessoas e a renda recebida.

O princípio 80/20 afirma que uma minoria de causas, inputs ou esforços normalmente conduz a uma maioria dos resultados, produtos ou recompensas. Assim, para todas as finalidades práticas, quatro quintos do esforço uma parcela dominante são em grande parte irrelevantes (KOCH, 2000).

Segundo Slack et al (2009), essa relação de Pareto pode ser usada para classificar diferentes tipos de itens mantidos em estoque por sua movimentação de valor. Isso permite que os gerentes de estoque concentrem seus esforços em controlar os itens mais significativos do estoque:

a) Itens classe A: são os $20 \%$ de itens de alto valor que representam cerca de $80 \%$ do valor total do estoque.

b) Itens classe B: são aqueles que de valor médio, usualmente os seguintes $30 \%$ dos itens que representam cerca de $10 \%$ do valor total.

c) Itens classe C: são os itens de baixo valor que, apesar de compreender cerca de $50 \%$ do total de tipos de itens estocados, provavelmente representam cerca de $10 \%$ de valor total de itens estocados.

A representação gráfica da curva $\mathrm{ABC}$ pode ser vista na Figura 4. 


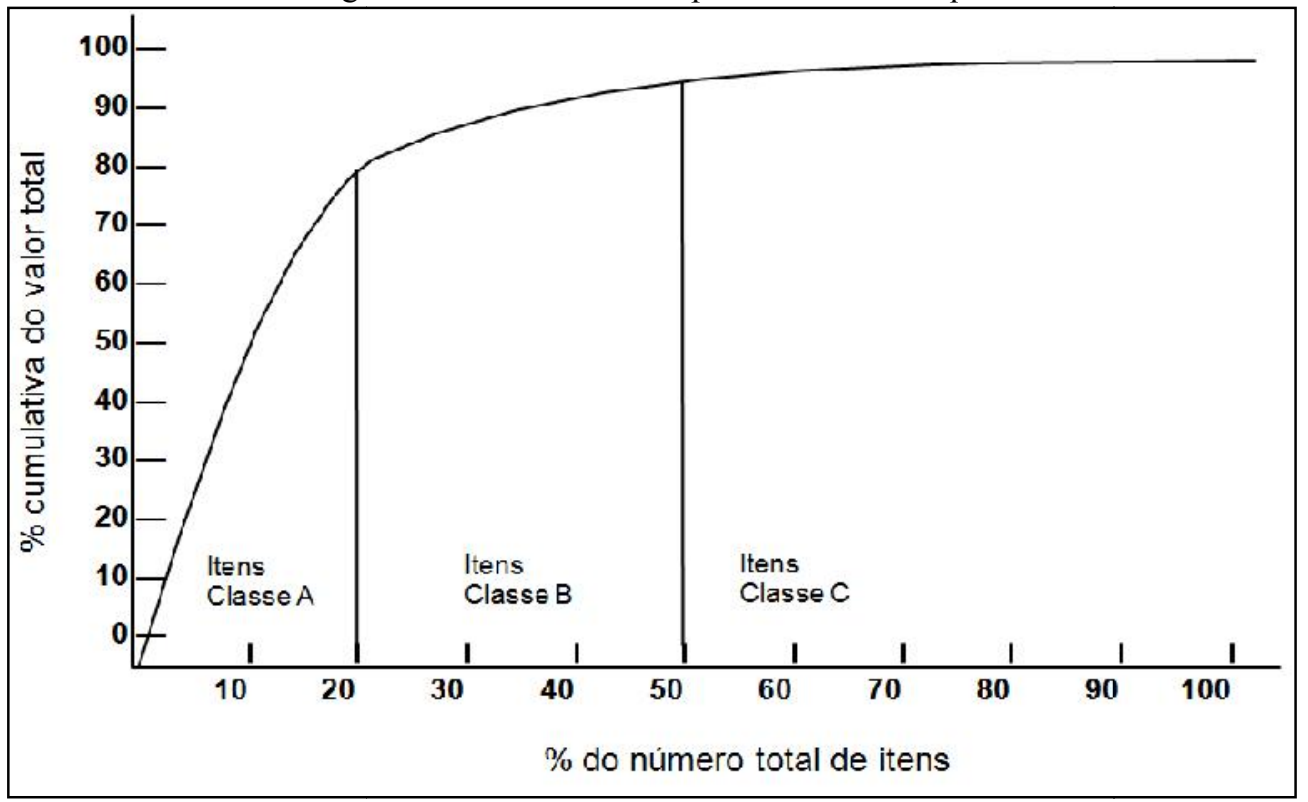

Fonte: SLACK et al $(2009, \mathrm{p} .403)$

De acordo com Pozo (2010), a grande vantagem da utilização da curva ABC é a classificação dos itens de estoque em classe A, B, C, com base em seus custos, quantidades ou outros fatores. Os itens mais importantes são em pequenos números e de mais alto valor, logo, devem ser controlados de forma mais rigorosa. Isso é possível, pois apesar desse controle rigoroso ser mais caro para a empresa, ele será feito sobre uma variedade mínima de itens.

Mas vale ressaltar, que com as constantes mudanças nos ambientes corporativos e tecnológicos, em um dado momento, um item que se enquadra como classe A, pode em outra situação não muito distante, figurar como classe B ou até mesmo C e vice versa. Assim, mesmo que um cálculo automatizado indique a classificação de um material como $\mathrm{A}, \mathrm{B}$ ou $\mathrm{C}$, essa situação não é definitiva e precisará ser reavaliada periodicamente.

\subsubsection{Classificação XYZ}

A classificação XYZ é muito semelhante à curva $\mathrm{ABC}$, no entanto, sua classificação é baseada na importância operacional dos itens, caracterizada pela fundamental necessidade dos mesmos em relação aos demais itens do estoque e não nos valores financeiros deles.

Para Lourenço e Castilho (2009), a classificação XYZ avalia a criticidade ou imprescindibilidade do material no desempenho das atividades realizadas. Perguntas como "Esse material é necessário para alguma atividade vital da organização?"; "Esse material pode ser adquirido facilmente?"; "O fornecimento desse material é problemático?"; "Esse material possui equivalente quanto à utilidade?" trazem as respostas que verificam o grau de importância desse produto dentro do estoque da organização.

Outra forma de entender essa classificação é em relação ao comportamento e demanda. Os itens com comportamento regular ou contínuo são classificados com itens $\mathrm{X}$ e os itens com 
comportamento irregular ou demanda baixa como itens Z. Os itens classificados como Y, são caracterizados de acordo com a estratégia utilizada pela organização. Essa classificação acontece através de análises estatísticas em certo período de tempo que permita verificar a curva completa de comportamento de demanda (SCHÖNSLEBEN, 2007).

Segundo Juran (1995), o método análise da criticidade ou classificação XYZ, assegura que sejam tomadas ações adequadas em relação a todas as características críticas. Fatores como segurança do produto ou a continuidade do fornecimento de energia elétrica são necessidades críticas aos clientes. Logo, a análise da criticidade visa fornecer subsídios para a tomada de decisão dos gestores, identificando características para que certos produtos, considerados críticos, recebam atenção especial.

Assim, a principal vantagem da classificação XYZ é a possibilidade minimizar ao máximo a falta de itens essenciais para o desenvolvimento das atividades principais da organização, que interrompam uma operação, por exemplo, além de priorizar os materiais de consumo e planejar possíveis alternativas para os itens que permitem substituição.

\section{Metodologia}

\subsection{A coleta de dados}

O levantamento de dados aconteceu nos meses de agosto e setembro de 2013, por meio de visitas in loco e entrevistas não estruturadas com os Analistas de Logística Integrada e de Planejamento de Materiais, onde foram solicitados os dados iniciais relativos aos itens do estoque necessários para a análise e aplicação dos modelos, tais como quantidade de itens MRO em estoque, grupo ou família, lead times de entrega, custo, levantamento de necessidades, retiradas de materiais para consumo, devoluções ao almoxarifado, estoque de segurança e PR.

Em seguida, foi feita uma análise para determinar quais itens seriam trabalhados, já que foi identificada a existência de itens que são mantidos em estoque para algum imprevisto que possa vir a ocorrer, no entanto estes itens podem permanecer por anos no estoque sem utilização alguma (sem giro) e o objetivo deste estudo é analisar apenas os itens com movimentação. Foi constatada ainda, a existência de itens obsoletos, que não serão mais utilizados, mais que contabilmente ainda permanecem em estoque. Ou seja, foi preciso calcular o giro de todos os materiais, para classificar quais seriam utilizados neste trabalho.

A etapa seguinte foi a aplicação de questionários semiestruturados para levantar informações sobre as dificuldades e oportunidades da área e do grupo de materiais (MRO), tais como o sistema utilizado para controle do estoque, metodologia para definição de ponto de ressuprimento, existência de previsão de demanda ou não, tipos de manutenções realizadas, entre outros. 


\subsection{Análise dos dados}

Os dados disponibilizados pela empresa foram dispostos em planilhas eletrônicas (Excel), onde as informações foram compiladas para possibilitar a aplicação das metodologias curva $\mathrm{ABC}$ (por custo acumulado consumido e custo unitário) e XYZ (por volume consumido no período) e posteriores análises das informações geradas e comparações com outros estudos realizados para encontrar similaridades e diferenciação para o estoque MRO.

Em seguida, foi realizada uma fusão entre os resultados de relevância dos materiais por custo e importância operacional nos processos, para então selecionar quais são os itens realmente críticos no estoque, em termos operacionais e também financeiros para identificar qual deveria ser o foco principal no gerenciamento destes materiais.

Por fim, foi levantado o tipo de política atual de ressuprimento desses itens para verificar sua eficiência em relação ao atendimento satisfatório da demanda, onde foi calculado o nível de serviço ofertado a partir da demanda reprimida identificada. De acordo com o resultado obtido, foi avaliada e confirmada a necessidade de proposição novas políticas de forma a melhorar este nível de serviço, mantendo controle eficiente dos custos, e assim, novos PR's foram propostos para alguns itens, conforme necessidade levantada.

\section{Resultados e discussão}

\subsection{Caracterização do estoque MRO}

O estoque de itens MRO na empresa estudada é composto por uma diversidade muito grande de materiais. Atualmente são 70.146 itens válidos e estão divididos entre os tipos 1, 2, 3, 4 e 5. Estes não são os nomes reais dos grupos de materiais, no entanto, para manter a confidencialidade das informações, optou-se por essa nomenclatura genérica.

- Tipo 1: São itens com reposição de estoque definidas. Faz parte deste grupo a grande maioria dos materiais MRO, com 43.581 itens.

- Tipo 2: São bens de ativo fixo, com aplicação específica, cujos parâmetros são definidos pela manutenção, com reposição através de ordem planejada. Existem 5.448 itens com esta classificação.

- Tipo 3: São bens patrimoniais, tais como equipamentos, máquinas ou sobressalentes recuperáveis, geralmente, com alto custo de aquisição. Integram este grupo 5.054 itens.

- Tipo 4: São materiais de compra direta, ou seja, são itens adquiridos com débito diretamente na área solicitante, destinados à aplicação direta e consumo imediato. Estes itens não são estocáveis e as requisições de compra serão emitidas pelos usuários. Esta lista contempla 15.976 itens. 
- Tipo 5: São materiais intermediários que sofrem desgaste com a matéria-prima ou o produto, não recuperável. Sua reposição é feita mediante reserva do usuário. São utilizados diretamente na produção e não podem retornar ao estoque, existem 87 itens tipo 5. (Exemplo, tijolos refratários, vestimentas, peneiras, telas, filtros, etc.).

Para desenvolvimento deste estudo foram utilizados apenas os materiais integrantes à classificação 1, já que apenas estes são os itens que trabalham com pontos de reposição de estoque. Além disso, cabe ressaltar que este grupo é composto por mais de $62 \%$ do estoque total da empresa, conforme mostrado na Figura 5.

Figura 5 - Composição do Estoque MRO

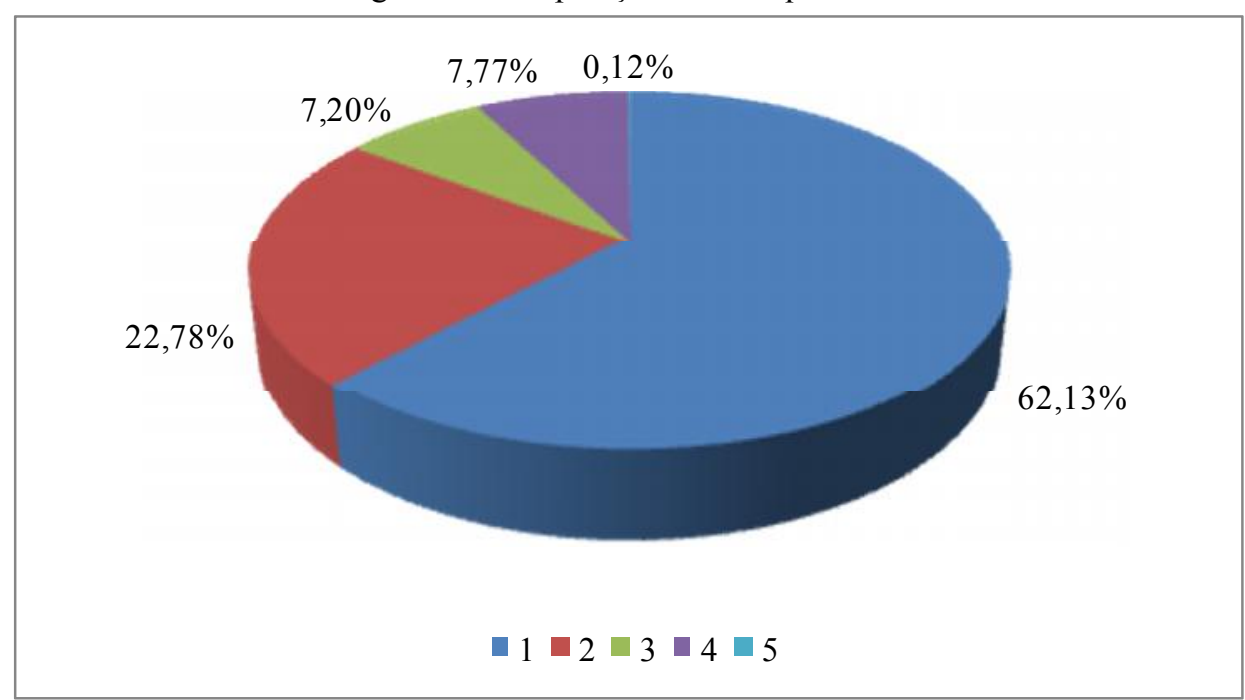

Fonte: Autoria própria (2014)

$\mathrm{O}$ controle de todas as informações relativas às movimentações de materiais (entradas, saídas, devoluções, etc.) é feita com o auxílio do sistema de informação integrado (software) $\mathrm{SAP} / \mathrm{R} 3$, através do MRP - material requirements planning ou planejamento das necessidades de materiais. Esta ferramenta é responsável pela gestão automática do ponto de ressuprimento dos estoques, com base em parâmetros pré-cadastrados.

No início do levantamento e análise dos dados, foi possível identificar que o giro do estoque utilizado na empresa, apesar de ser uma informação de grande importância, não era muito avaliado ou mesmo mensurado. Além disso, o conceito de giro utilizado pelos colaboradores tem um fundamento diferente em relação ao mencionado anteriormente na subseção 4.5 deste trabalho. Para a empresa, giro é a quantidade de pedidos (ou compras) de um item realizados no período de análise, não caracterizando o consumo efetivo e nem as devoluções. As equipes de manutenção e de outras áreas da empresa podem fazer retiradas e, posteriormente, devolver o estoque não utilizado dos itens MRO. 
Para o desenvolvimento desta etapa do trabalho, foram extraídas diversas planilhas eletrônicas diretamente do SAP, que continham as informações sobre as aquisições, atendimentos, devoluções e saldo no início do período de análise (outubro de 2012 a setembro de 2013, completando um ciclo anual). Assim, o cálculo do giro se deu a partir da Equação 3. As Equações 4 e 5 permitem fazer o ajuste dos dados da empresa para determinar o efetivo consumo e saldo do período, segundo a definição da literatura.

$$
\text { GirodoEstoque }=\frac{\text { Consumo }}{\text { SaldonoPeriodo }}
$$

Onde,

$$
\text { Consumo = Quantidaderetirada-Quantidadedevolvida }
$$

e,

$$
\text { SaldonoPeriodo }=\text { Saldoanterior }+ \text { Aquisiçôesnoperiodo }
$$

Com o cálculo do giro dos materiais, foi possível perceber que a quantidade efetivamente movimentada é muito pequena em relação ao tamanho total do estoque. No período de análise, apenas 5.443 itens apresentaram algum tipo de movimentação, sendo que 27 destes itens foram apenas adquiridos no período, mas não houveram retirada pelos usuários, ou seja, menos de 12,5\% do total de itens em estoque foi consumido no último ano.

Alguns destes itens não movimentados no último ano são estratégicos para a empresa e, portanto, precisam ser mantidos em estoques para necessidades futuras, mesmo que em baixo volume, estes são os materiais chamados de A3, com valores geralmente elevados e consumo esporádico.

No entanto, a parcela desses itens estratégicos é pequena em comparação com o total, pois totalizam apenas 319 itens a um custo de $\mathrm{R} \$ 724.837,60$. Os demais itens não movimentados tornam-se um problema para a empresa, pois esta estagnação origina um custo de oportunidade elevado, já que o valor empenhado nestes materiais poderia ser direcionado a outros projetos ou investimentos pela empresa, e esta situação é mal vista pelos investidores e também pelo mercado.

Existe ainda um grande número de materiais no estoque sem expectativa alguma de utilização, são os chamados "itens sem condições de uso". Essa situação pode acontecer por dois motivos específicos, ou o material tornou-se obsoleto, por exemplo, uma peça de reposição para um equipamento que foi substituído por outro mais moderno ou então o lançamento de uma nova versão, ou mudança de tecnologia, tipo de material não atende mais, etc. O segundo motivo é 
quando o material não se encontra em condições de uso, podendo estar, deteriorado, quebrado, ressecado, desgastado, amassado, ou com vazamento conforme pode ser visto nas Figuras 6 e 7.

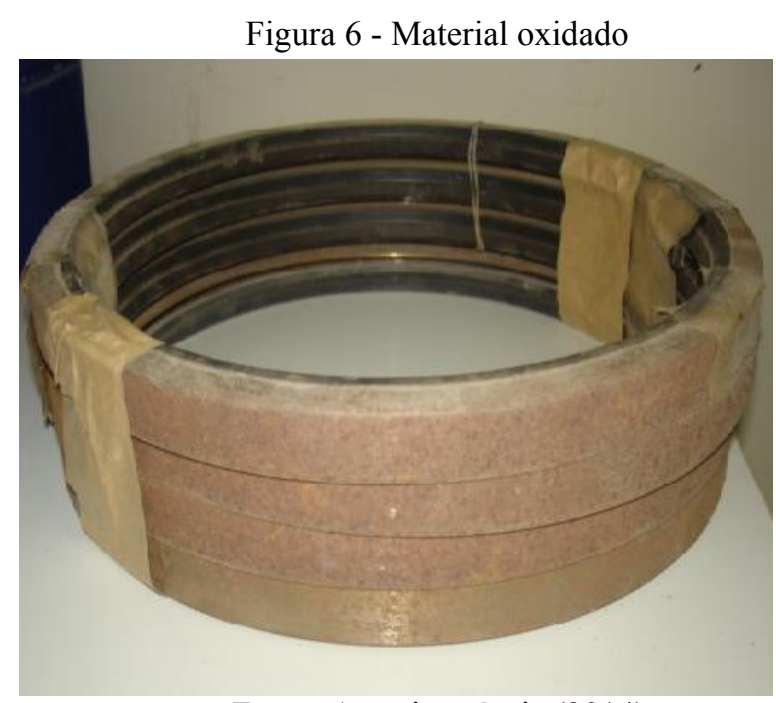

Fonte: Autoria própria (2014)



Fonte: Autoria própria (2014)

Os motivos que levam estes materiais a perderem sua utilidade são diversos, tais como a ação do tempo, estocagem inadequada, manuseio equivocado, falta de manutenção, queda, entre outros. Nessas condições, deve-se avaliar a possibilidade de recuperação do material através da abertura de uma nota AMV - Aviso de Material para Verificação - para a Oficina correspondente ao material para realização conferência técnica. Constatando-se a inutilização do material, deve-se bloquear seu saldo no sistema e providenciar a regularização contábil (nas áreas de Controladoria e Patrimônio) e, por fim, solicitar a descaracterização do material e sua transferência para a área de armazenagem de sucata compatível com o tipo de material.

Este procedimento é visto pelas áreas da empresa, como burocrático e trabalhoso. Assim, alguns usuários preferem manter estes materiais no estoque do almoxarifado, mesmo sem a possibilidade de utilização. No entanto, essa situação não é a ideal, já que gera um custo de armazenagem, além de elevar o nível do estoque de forma errônea.

\subsection{Necessidades e atendimentos de materiais}

O estoque de itens MRO atende, na sua grande maioria, às diversas oficinas de manutenção da empresa (elétrica, mecânica, hidráulica, etc.), que através de reserva feita no SAP, gera uma necessidade de compras para a área de suprimentos ou uma liberação de retirada no almoxarifado, se existir estoque suficiente para o material requisitado.

$\mathrm{O}$ atendimento de materiais feito pelo almoxarifado sempre utiliza o conceito FIFO - First In, First Out, ou primeiro que entra é o primeiro que sai, para que os materiais mais antigos sejam utilizados antes dos adquiridos mais recentemente. Apenas nas situações onde houverem DAG Devolução ao Almoxarifado Geral, esta regra não é utilizada, pois este tem a prioridade de saída. 
Essas DAG's provocam algumas dificuldades nas análises da movimentação do estoque, mascarando o giro e o consumo real. Além disso, outros problemas podem ser apontados, tais como, compra desnecessária e aumento do nível e custo do estoque, pois, por exemplo, no início do mês um item que possui um saldo de 20 unidades e o PR de 10, onde um colaborador retira 15 peças (o estoque fica com apenas 5 unidades de saldo), gerando uma necessidade de compra imediata para a área de suprimentos. No entanto, no final deste mesmo mês, o colaborador devolve 10 das peças que havia retirado ao almoxarifado e não utilizou, logo o saldo fica com 15 unidades (acima do PR), mas a compra já foi realizada. Ou seja, gastou-se uma quantia na aquisição de um material que não precisava ser realizada neste momento e ainda aumentará o custo de estocagem. Os principais fatores levantados que motivam a devolução dos materiais ao estoque podem ser:

- O material retirado não atendia a necessidade do usuário (tamanho, formato, constituição ou outras características);

- Não utilização de toda a quantidade retirada (usuário solicitou uma quantidade superior à necessária);

- Cancelamento da atividade em que o material seria utilizado; e

- Orçamento excedido (o usuário devolve o material ao estoque para reduzir os custos no final do mês e não exceder ao que foi orçado).

Outra situação que pode gerar dificuldades em termos de planejamento e programação das necessidades é a falta de acompanhamento do comportamento da demanda pelos itens MRO. Estes materiais possuem características de consumo diferenciadas entre si, o que não significa que não seja possível estudar o comportamento de algumas classes e evitar:

- Pagamento de fretes emergenciais com preços elevados;

- Risco da indisponibilidade do fornecedor (parceiro) de atendimento à demanda imediata, sendo necessária a busca por outros canais ou fontes;

- Atraso no desenvolvimento de alguma atividade que dependa dos materiais;

- Interrupção de algum processo produtivo.

Além disso, o estudo do comportamento da demanda pode informar alguma tendência de consumo, que permita a obtenção de ganhos gerais, tais como redução do custo do pedido, determinação de Lote Econômico de Compra, negociação com fornecedores, e etc.

Cabe ressaltar que é feito um planejamento de demanda por parte desses itens apenas em períodos de Paradas Gerais (PG) e, ou, Setoriais com atividades intensas. Estas programações são realizadas com base nos dados históricos (da Parada equivalente do ano anterior) e necessidade 
informada pela área de Manutenção. Essa análise é realizada de forma manual e contempla os itens de forma individual.

Com as PG's, as demandas pelos itens MRO aumentam consideravelmente, conforme apresentado na Figura 8. Na empresa alvo deste estudo acontecem duas paradas anuais programadas (uma em cada linha de operação principal). Outras paradas menores em diversos setores podem ocorrer durante o ano, de forma planejada ou por motivo de emergência (por dano de equipamento, acidente ou incidente, redução da capacidade de operação, etc.).

Figura 8 - Demanda anual por itens MRO

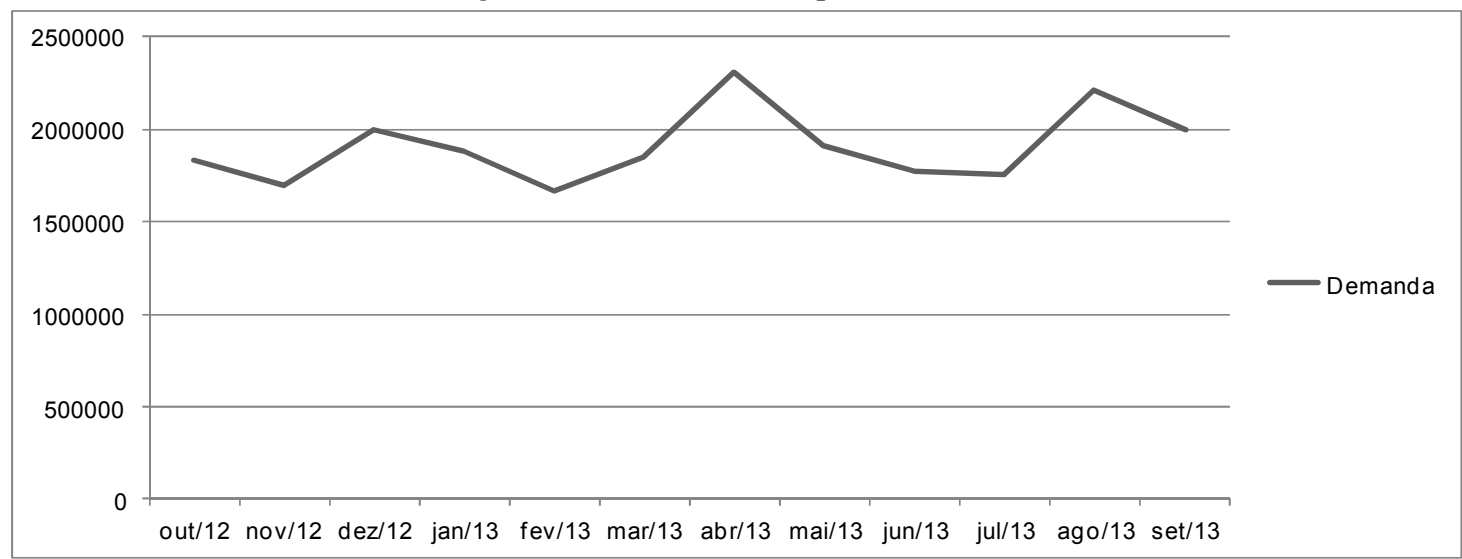

Fonte: Autoria própria (2014)

Ao analisar o consumo mensal do estoque MRO, foi possível identificar presença da sazonalidade da demanda em decorrência dessas Paradas Gerais, em que as maiores quantidade de itens são consumidas exatamente nos meses de abril e agosto.

Neste contexto, um sistema de manutenção permanente poderia ser adotado pela Empresa no intuito de reduzir as incertezas e risco de ruptura. A manutenção produtiva total - MPT é um programa que surgiu no Japão na década de 70, a partir de um avanço em relação às técnicas e procedimentos tradicionais da manutenção corretiva, preventiva e preditiva que delega aos operadores a responsabilidade de conservar em boas condições de funcionamento os recursos (ANTUNES, 2008).

Ahmed et al (2005) afirma que um plano de implementação do TPM bem desenvolvido, não só melhora eficiência de equipamento, mas também traz melhorias apreciáveis em outras áreas como redução de tempo de ciclo industrial, tamanho de inventário, reclamações de cliente, e cria grupos pequenos de equipes de trabalho semiautônomos, onde há o aumento da habilidade e confiança dos indivíduos. Ou seja, o resultado encontrado é uma empresa mais produtiva.

Desta forma, o trabalho de conservação das máquinas, equipamentos e materiais diversos, passa a ser preocupação de todos, desde o operador do processo até a diretoria de manutenção, o que faz do TPM uma estratégia para aumento de produtividade e qualidade, já que possibilita uma 
produção com custos menores, com maior qualidade e confiabilidade e ainda reduzindo desperdícios e riscos.

\subsection{Ponto de ressuprimento/aquisição de materiais}

De acordo com a retirada dos materiais no almoxarifado, vai-se reduzindo o saldo até atingir o PR do item. Neste momento, é disponibilizada aos compradores do grupo de materiais em questão, uma relação com as necessidades de compra, que tem um prazo máximo de 3 dias (pelo ANS - Acordo de Nível de Serviço, firmado) para efetivar a compra. Ressalta-se, no entanto, que este prazo nem sempre é respeitado.

A política de ressuprimento utilizada na empresa é de revisão contínua, já que as decisões de reabastecimento podem ser tomadas a qualquer instante de tempo, basta que o estoque mínimo seja atingido. Segundo informações coletadas na entrevista, uma vez por ano é feita essa revisão pelos próprios compradores com base no consumo anual. Com a finalidade de evitar compra desnecessária e, ou, obter ganhos com o custo de pedido, LEC, etc.

A partir do questionário aplicado, foi possível identificar que a política de revisão contínua é a $(\mathrm{s}, \mathrm{S})$, de acordo com a teoria apresentada na subseção 2.10.2., onde toda vez que a posição de estoque atinge um nível de $\mathrm{S}$ unidades (abaixo do PR), é feito um novo pedido de tamanho suficiente para elevá-lo ao máximo.

Os PR's dos itens MRO são informados pela equipe de manutenção no ato do cadastramento da RME - Recomendação de Material para Estoque. Esses parâmetros informam a quantidade em estoque na qual deve-se iniciar uma nova compra. No momento em que o saldo físico está abaixo do PR, prepara-se uma ordem de compra, onde são consideradas também, as quantidades em processo de aquisição que ainda não foram recebidas.

Dentro da tipologia de itens 1 , existem basicamente três parâmetros de ressuprimento diferentes (MRP):

Tipo de MRP A1 - São itens utilizados na produção com o ponto de reabastecimento definido. São repostos de acordo com os dados de gestão que foram parametrizados no SAP, a partir da necessidade gerada pelo usuário através da criação de uma reserva.

Tipo de MRP A2 - São itens utilizados na manutenção e repostos automaticamente de acordo com os dados de gestão que foram definidos e parametrizados no SAP, sem necessidade de consulta ao usuário. A reposição acontece até o estoque máximo.

Tipo de MRP A3 - São os itens estratégicos. Estes materiais geralmente têm alto custo, baixo giro e demandam maior tempo para sua aquisição (já que alguns são importados). As estratégias de reposição são definidas pela área de Manutenção e têm prioridade de compra.

A lista dos itens estratégicos conta com 319 itens cadastrados, conforme já mencionado. 
Alguns exemplos destes itens são os motores, rotores, gaxetas, bombas e vários outros. Estes materiais são responsáveis pela garantia operacional. São geralmente itens caros e sem previsão de consumo, merecendo atenção especial em relação aos demais itens do estoque. Também é considerado estratégico ou crítico o material que, na sua falta e necessidade, além de perda de produção acarretam risco de segurança ou ao meio ambiente e perda ou descontrole de qualidade.

O Lote Econômico de Compra é sempre levado em consideração ao se realizar um pedido, principalmente em materiais com alta rotatividade e, ou, baixo valor unitário. Este fato é motivado pela longa distância dos fornecedores até a unidade fabril, além do custo dos pedidos (tempo de trabalho, telefone, fretes, etc.). Os fornecedores estão, em sua grande maioria, localizados em São Paulo e no Sul do país. Somente são adquiridos materiais na região próxima à localização da fábrica em casos emergenciais. A justificativa informada refere-se ao fato dos valores cobrados localmente serem muito mais elevados e a quantidade disponível não atender a demanda necessária.

\subsection{Curva ABC}

O Princípio de Pareto ou Curva ABC permite que os esforços sejam concentrados nos itens de maior importância financeira. Para esta análise foi utilizada a classificação 1 com as seguintes considerações:

- Apenas os itens que tiveram alguma movimentação no período de análise (1 ano) foram contabilizados;

- Foram desconsiderados desta relação inicial alguns materiais (53 itens no total) que foram reclassificados com valores diferentes do mercado para que não haja interferência nos resultados.

Para o desenvolvimento desta etapa foi utilizada uma relação de 5.390 itens, em que o valor total de itens consumidos no período foi de $\mathrm{R} \$ 30.140 .427,74$. Ao se realizar a relação entre porcentagem para cada item da Curva $\mathrm{ABC}$ com a quantidade de itens no estoque, foi encontrado um resultado ainda maior do que o indicado na literatura, em que os $20 \%$ que receberam a classificação A foram responsáveis por mais de $90 \%$ do valor de estoque, conforme Tabela 1. Este resultado indica uma elevada concentração em valor de poucos itens do estoque.

Tabela 1 - Classificação ABC por valor consumido

\begin{tabular}{cccrc}
\hline Classificação & Quantidade de Itens & \% & \multicolumn{1}{c}{ Valor } & \% \\
\hline A & 1078 & $20 \%$ & $\mathrm{R} \$ 27.324 .727,87$ & $90,66 \%$ \\
$\mathrm{~B}$ & 1617 & $30 \%$ & $\mathrm{R} \$ 2.433 .705,63$ & $8,07 \%$ \\
$\mathrm{C}$ & 2695 & $50 \%$ & $\mathrm{R} \$ 381.994,24$ & $1,27 \%$ \\
Total & $\mathbf{5 3 9 0}$ & $\mathbf{1 0 0 \%}$ & $\mathbf{R} \mathbf{3 0 . 1 4 0 . 4 2 7 , 7 4}$ & $\mathbf{1 0 0 , 0 0 \%}$ \\
\hline
\end{tabular}

Fonte: Autoria própria (2014) 
A partir destes dados foi possível traçar a curva $\mathrm{ABC}$ real, conforme apresentado na Figura 9.

Figura 9 - Curva ABC para Estoque MRO (valor total consumido)

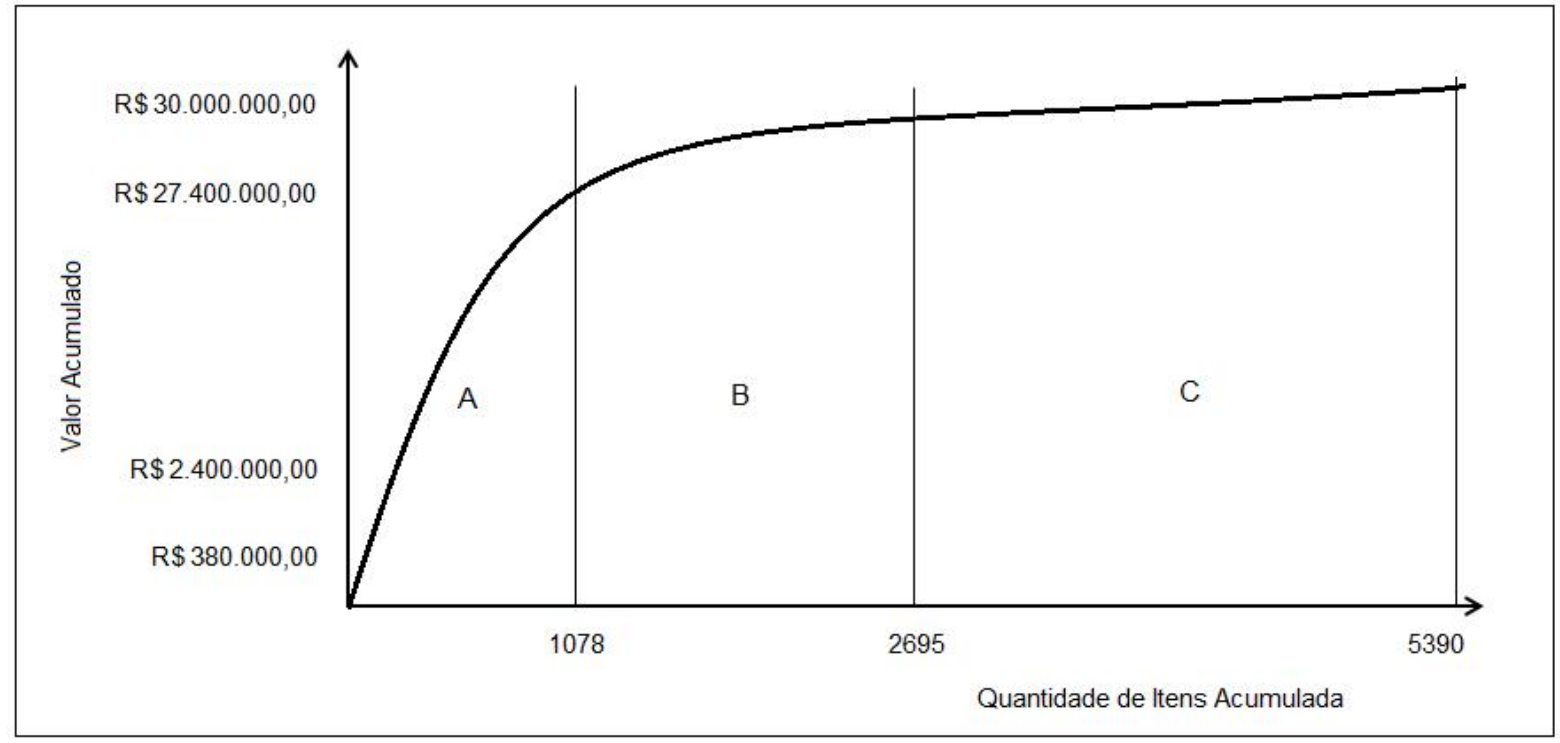

Fonte: Autoria própria (2014)

Em um estudo semelhante, Oliveira (2013) também estudou o comportamento dos itens MRO em uma fábrica de rolamentos e encontrou um percentual de $82,52 \%$ do valor acumulado, em $20 \%$ dos itens (os classificados como itens A), que, apesar de ser um valor inferior ao encontrado neste estudo, ainda supera ao indicado pela metodologia.

$\mathrm{Na}$ literatura, é possível identificar que, a característica 80-20 se apresenta na maioria dos casos (para estoques de matéria prima e produto acabado, por exemplo). Briozo (2011) estudou o impacto da curva $\mathrm{ABC}$ no agronegócio brasileiro e realizou um estudo de caso em uma empresa processadora de vegetais orgânicos no Paraná, em que o objetivo da classificação era identificar quais produtos tinham a maior demanda visando uma melhoria de layout na câmara fria. Assim, a curva $\mathrm{ABC}$ foi construída em relação ao volume de vendas. A partir dos dados informados no anexo deste estudo, foi possível identificar sua disposição da seguinte maneira: dos 213 itens estocados, 43 (ou 30\%) são classificados como A, logo, 79\% das vendas estão concentrados nesta menor quantidade de produtos. Integrando a divisão B estão 64 itens (ou 30\%), correspondendo a 17\% das vendas. Os demais (64 itens, ou 50\% restantes) compõem a classificação C, que são responsáveis apenas por $4 \%$ das vendas.

Cardozo, Cittadin e Ritta (2011) realizaram um estudo sobre gestão de estoques em uma empresa atacadista de materiais de construção de Santa Catarina e utilizaram a ferramenta de Pareto para classificar os produtos adquiridos. Os resultados encontrados foram que $19,71 \%$ dos itens equivalem a $80,58 \%$ em valor financeiro no estoque, estes são os itens classe A, $24,44 \%$ são itens 
classe B e correspondem a 14,08\% dos valores e 55,85\% dos itens restantes pertencem a classe C e têm a menor participação, com 5,34\% do valor total do estoque.

Panzuto e Rodrigues (2010) também realizaram um trabalho semelhante sobre gestão de estoques em uma pequena empresa do setor de autopeças em Bauru, São Paulo. Na classificação ABC elaborada, os produtos que compõem a classe A são aproximadamente $17,46 \%$ de todos os produtos acabados e possuem uma influência financeira de aproximadamente $80,66 \%$. Os itens B correspondem a $26,98 \%$ dos itens e $15,32 \%$ do valor total e, por fim, os itens da classe C são a maioria $(55,56 \%)$ dos itens, mas correspondem a apenas $4,02 \%$ do valor total do estoque da empresa.

Ao realizar uma análise pela mesma regra de Pareto do ponto de vista dos autores Panzuto e Rodrigues (2010), acima citados, onde o levantamento é feito a partir do valor acumulado, ou seja, deve-se identificar qual o percentual de itens é responsável por $80,01 \%$ do valor do estoque (R\$ 24.112.342,19). O resultado mostrou que esta quantia $(80,01 \%$ do valor) está concentrada em apenas 563 itens, ou 10,44\% dos itens estudados. O resultado encontrado evidencia e ratifica a alta concentração do valor de estoque MRO em uma pequena quantidade de materiais.

Estes estudos mostram que a teoria de Pareto, ou Curva ABC, é bastante condizente com a realidade para os estoques de matéria prima e também de produto acabado. No entanto, de acordo com o que foi encontrado no presente estudo, a concentração em valores monetários é maior para estoques de itens MRO.

A partir da classificação realizada neste trabalho, outra análise foi realizada utilizando a curva $\mathrm{ABC}$ em relação aos valores unitários dos materiais, no intuito de verificar se os itens com maior valor consumido no ano são também aqueles que possuem os valores individuais mais elevados.

A soma total dos valores unitários dos 5390 itens analisados é de $\mathrm{R} \$ 3.727 .135,65$, e o resultado evidenciou ainda mais a concentração, em valor de estoque, de poucos itens MRO. Os $20 \%$ que representam a classe $\mathrm{A}$, representam $92,54 \%$ do valor total do estoque, conforme apresentado na Tabela 2 .

Tabela 2 - Classificação ABC por valor unitário

\begin{tabular}{cccrc}
\hline Classificação & Quantidade de Itens & $\mathbf{\%}$ & \multicolumn{1}{c}{ Valor } & \multicolumn{1}{c}{$\%$} \\
\hline A & 1078 & $20 \%$ & $\mathrm{R} \$ 3.449 .195,89$ & $92,54 \%$ \\
$\mathrm{~B}$ & 1617 & $30 \%$ & $\mathrm{R} \$ 250.482,03$ & $6,72 \%$ \\
$\mathrm{C}$ & 2695 & $50 \%$ & $\mathrm{R} \$ 27.457,73$ & $0,74 \%$ \\
Total & $\mathbf{5 3 9 0}$ & $\mathbf{1 0 0 \%}$ & $\mathbf{R} \mathbf{3 . 7 2 7 . 1 3 5 , 6 5}$ & $\mathbf{1 0 0 , 0 0 \%}$ \\
\hline
\end{tabular}

Fonte: Autoria própria (2014) 
Com esses resultados, a empresa consegue identificar quais são seus itens mais onerosos, e assim, realizar uma política de gestão de estoques diferenciada, priorizando os itens classificados como A. A curva ABC para esta situação também foi traçada e pode ser vista na Figura 10.

Figura 20 - Curva ABC para Estoque MRO (valor unitário)

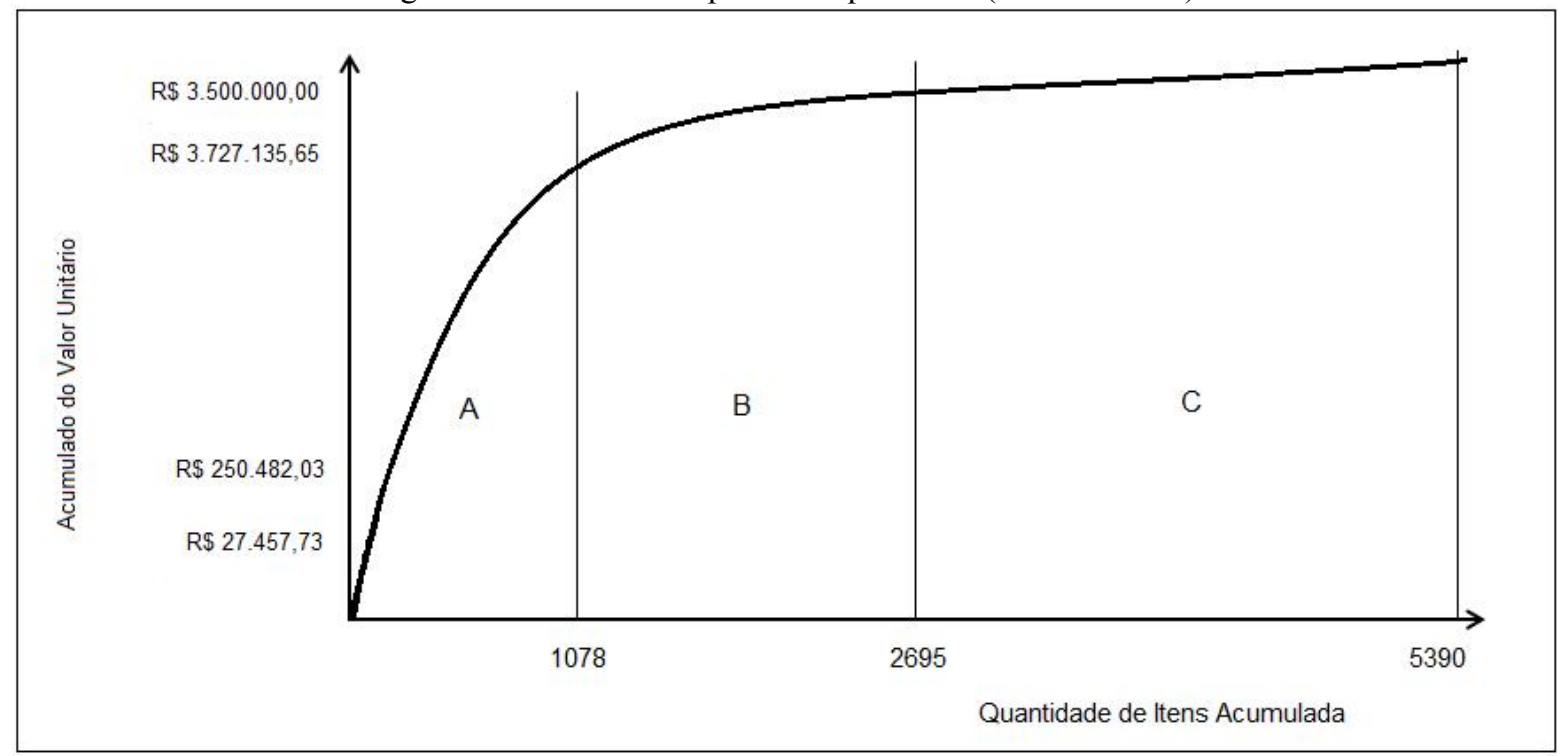

Fonte: Autoria própria (2014)

\subsection{Classificação XYZ}

Para a análise XYZ, foi utilizada a interpretação de Schönsleben (2007), em que a análise é feita em relação a quantidade consumida. Os itens cuja demanda apresenta comportamento contínuo, ou de maior consumo, são classificados como itens $\mathrm{X}$ e os itens com comportamento irregular ou demanda baixa como itens Z. Os itens classificados como Y são os intermediários.

Os resultados obtidos desta classificação foram combinados com os encontrados com a metodologia $\mathrm{ABC}$ para verificar uma possível relação entre as variáveis de custo total consumido e consumo efetivo. Os resultados são apresentados na Tabela 3.

\begin{tabular}{ccccc}
\multicolumn{5}{c}{ Tabela 3 - valor X consumo } \\
\hline Classificação & $\mathbf{X}$ & $\mathbf{Y}$ & $\mathbf{Z}$ & Total \\
\hline $\mathbf{A}$ & 205 & 347 & 525 & 1077 \\
$\mathbf{B}$ & 545 & 574 & 498 & 1617 \\
$\mathbf{C}$ & 327 & 696 & 1673 & 2696 \\
Total & 1077 & 1617 & 2696 & $\mathbf{5 3 9 0}$ \\
\hline Fonte: Autoria própria $(2014)$ & & &
\end{tabular}

Fonte: Autoria própria (2014)

Com este resultado é possível perceber que dos 1077 itens classificados como "A" pela regra de Pareto, apenas 205, ou 19\%, apresentaram uma importância significativa pelo ponto de vista do consumo e foram classificados como "X"; $32 \%$ destes itens estão entre os intermediários (os "Y"); e a maior parte, 49\% são itens com baixa demanda (itens “Z”). 
Figura 11 - Classificação XYZ dos Itens A

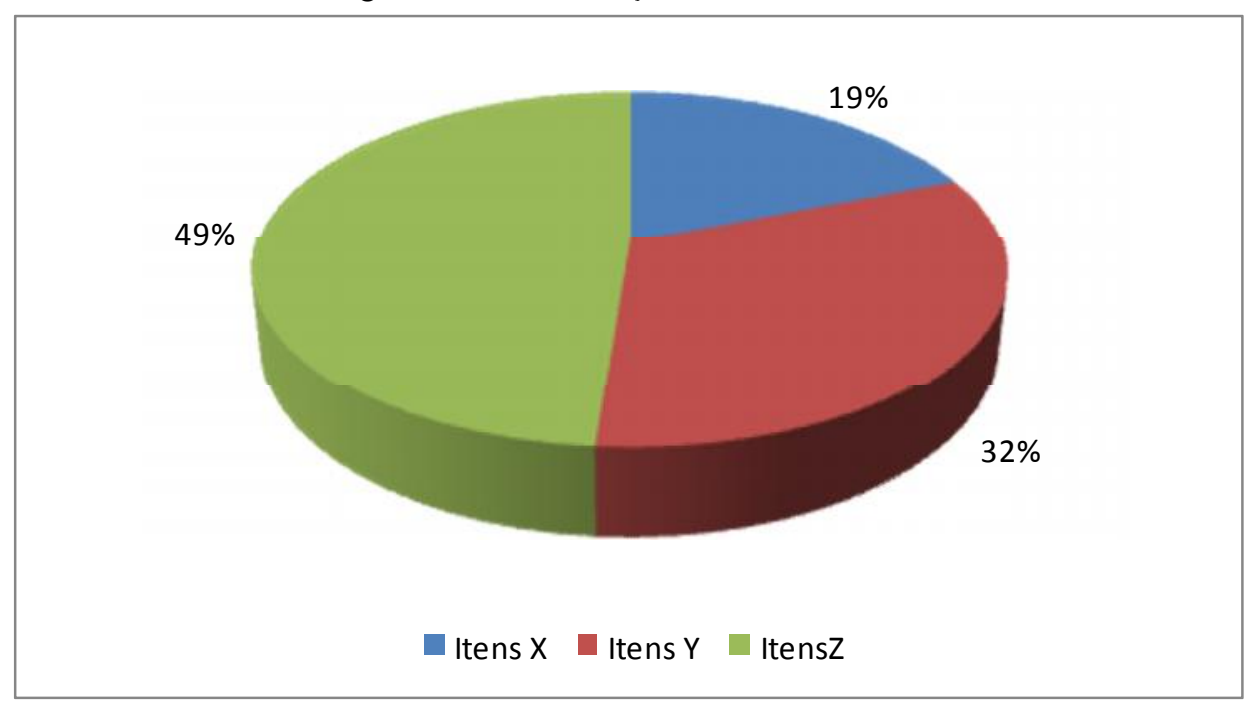

Fonte: Autoria própria (2014)

Em relação aos 1617 itens que receberam a classificação "B" na curva $A B C$, pode-se afirmar que a divisão foi equilibrada em relação à classificação XYZ, onde $34 \%$ foram " $X$ ", $35 \%$ foram "Y" e $31 \%$ foram "Z".

Figura 12 - Classificação XYZ dos Itens B

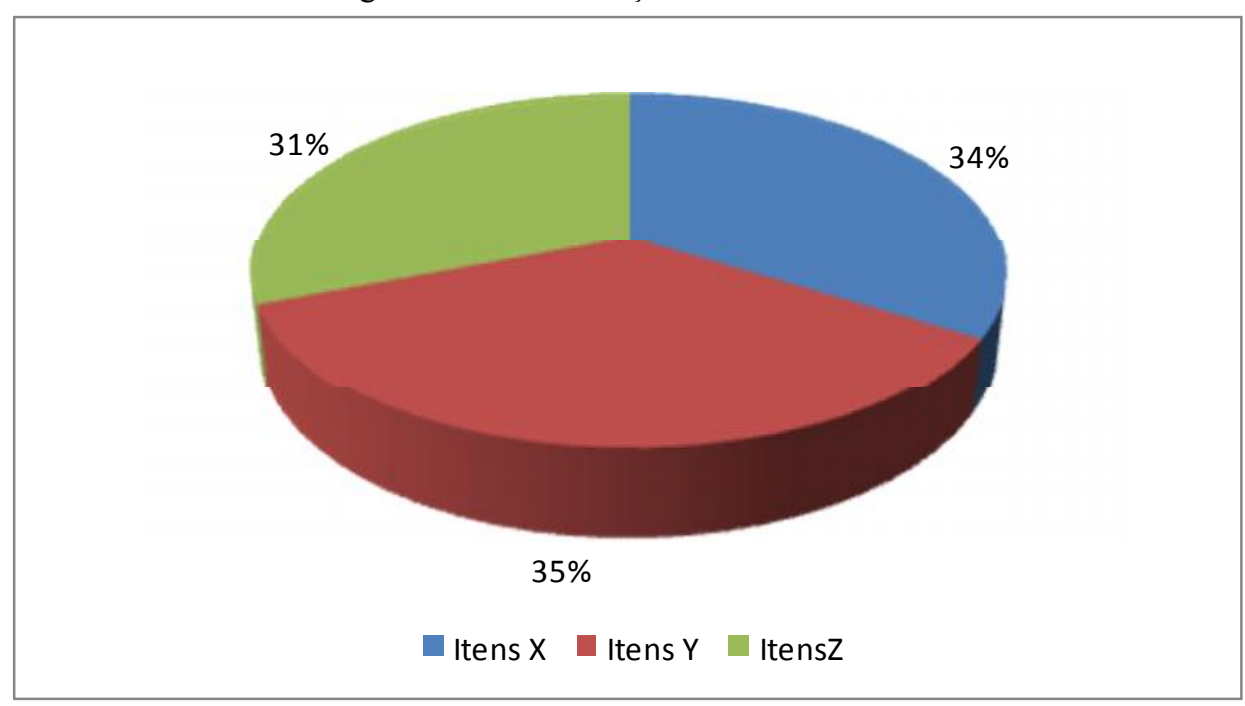

Fonte: Autoria própria (2014)

Por fim, os itens classificados como de menor importância financeira, os itens "C", tiveram sua divisão da seguinte forma: $12 \%$ em itens "X", $26 \%$ de itens "Y" e $62 \%$ são os chamados itens “Z”, ou seja, os que apresentam menor importância, tanto do ponto de vista do valor do material, quanto do seu consumo no período de análise. 
Figura 13 - Classificação XYZ dos Itens C

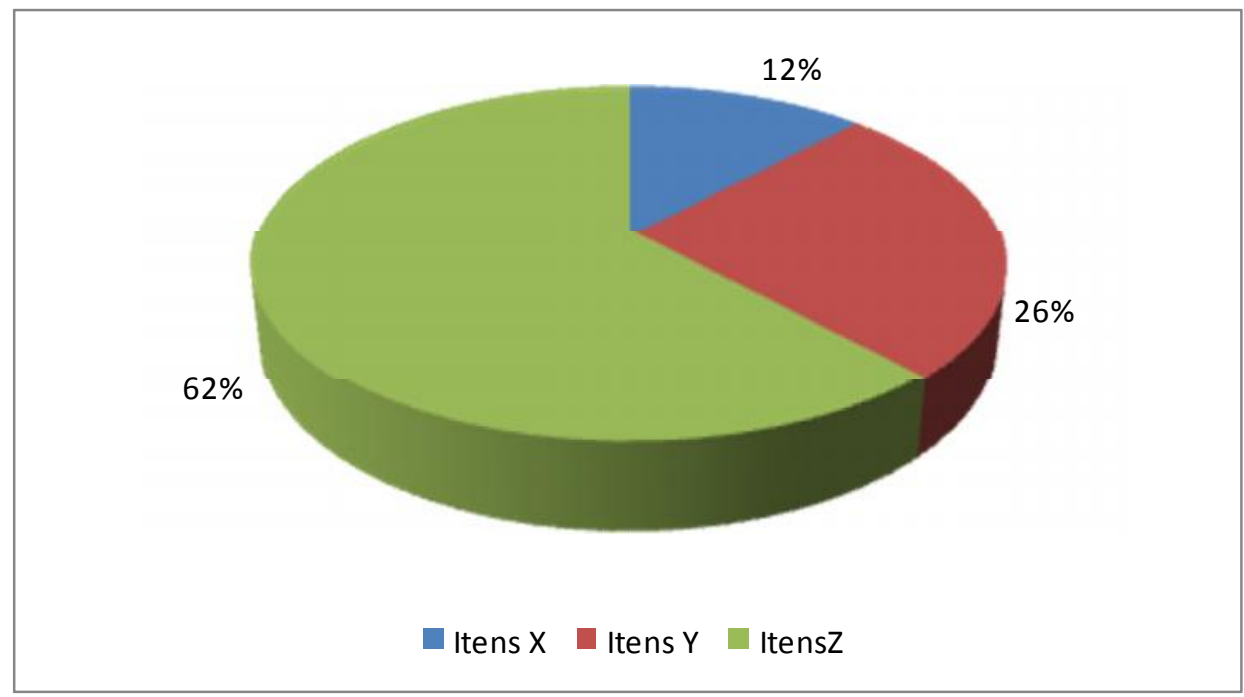

Fonte: Autoria própria (2014)

Assim, os itens que receberam a classificação A e também a classificação X (apenas 205), são os materiais mais críticos aos processos (por ambos os aspectos) e são os que os gestores precisam designar uma atenção especial, tanto no momento de sua aquisição, quanto na gestão específica. Como exemplo, em uma tentativa de minimização de estoque para redução de capital de giro, um trabalho realizado com estes itens irá fornecer um resultado mais significativo no desempenho global dos estoques do que aconteceria com esforços similares nos itens que foram classificados como CZ (apesar de ser a grande maioria). Os outros 32\% dos itens são BY e suas implicações no desempenho do sistema têm, portanto, relevância intermediária.

Após serem definidas as classes de itens do estoque, é possível o desenvolvimento de análises e a tomada de decisões a partir de uma visão global. Além disso, devido ao critério utilizado para a formação das classificações, custo e volume, as decisões podem ser embasadas na relevância de cada item.

Outros estudos apresentaram conclusões semelhantes, Rego e Mesquita (2011), por exemplo, realizaram um trabalho de revisão da literatura sobre o controle de estoque de peças de reposição, abordando tanto a previsão de demanda quanto o controle de estoques nos diferentes estágios do ciclo de vida das peças. Foi identificado que neste grupo de materiais existem itens com demanda elevada (em geral itens de maior desgaste e manutenção preventiva), mas a grande maioria possui demanda esporádica e, portanto, exigem ferramentas de gestão distintas.

Silva (2009) desenvolveu um modelo de estoque para peças de reposição sujeito à demanda intermitente e lead time estocástico em uma empresa multinacional do ramo de siderurgia. Considerando o comportamento apresentado pelas peças de reposição e os resultados dos modelos de estoque, o autor concluiu que as peças de reposição apresentaram grande variabilidade nos padrões de demanda, desde itens com baixíssimo giro (vários anos sem movimentação) até itens 
com alto giro com valor esperado da LTD superior a 5000 unidades. O autor levantou ainda, algumas das causas que contribuem para acentuar as características de irregularidade e intermitência das peças de reposição. Dentre elas, a utilização de diferentes técnicas de manutenção, consumo de itens de manutenção em projetos, desgastes prematuros no processo produtivo e utilização de estoques paralelos fora do sistema.

Portanto, uma característica percebida na gestão dos itens MRO é a maior dificuldade nas análises e definições dos parâmetros no controle dos estoques, já que cada grupo de itens é gerido por um conjunto de regras diferenciado, aumentando a complexidade do modelo e criando barreiras para sua adoção e implantação.

\subsection{Análise da eficiência dos pontos de ressuprimento}

Em relação ao ponto de ressuprimento (PR) destes materiais, foi possível identificar que 862 itens apresentaram alguma demanda reprimida (não atendida) no período de 1 ano (dos 5390 analisados). O nível de serviço ofertado é 0,88 ou $88 \%$ de disponibilidade dos materiais e foi medido em relação ao número de unidades em falta anualmente sobre a demanda total. Ou seja, há um risco considerável do cliente não encontrar o material necessário, ocasionando uma possível ruptura de processo. A análise deste resultado foi verificada de acordo com a classificação $\mathrm{ABC}$, e conforme mostrado na Tabela 4, a maior incidência de falta acontece entre os itens C, onde o nível de serviço é de $85 \%$, enquanto em relação aos itens $\mathrm{A}$, foi encontrado um nível de serviço de $91 \%$.



Estudos apontam que o nível de serviço oferecido pela empresa está dentro dos padrões aceitáveis pelos clientes. Bittencourt (2006) pesquisou sobre as necessidades/desejos dos clientes e definiu níveis de serviço logísticos adequados aos diferentes tipos de mercado ou produto. Com base em uma pesquisa realizada IMAM (Inovação e Melhoramento na Administração Moderna) em 16 setores da economia, foi feita uma análise inicial com os dez melhores em termos de desempenho em nível de serviço, tendo como resultado médio de nível de serviço, aproximadamente, 91,6\%. Por outro lado, quando foi considerada a amostra total dos dezesseis setores analisados, esse nível de serviço caiu para, aproximadamente, 83\%. Com base nesses resultados o autor considera uma faixa de nível de serviço adequado a partir dos $83 \%$ e um nível de serviço excelente até $91,6 \%$. Dessa forma, valores de nível de serviço que estiverem abaixo de $83 \%$ 
serão considerados "insatisfatórios" e os que estiverem acima de 91,6\% serão considerados "desperdício".

Silva (2008) também obteve resultados semelhantes em termos de nível de serviço do ponto de vista da disponibilidade em uma empresa de bebidas na Paraíba, já que esta empresa consegue atender a seus clientes em 89\% das solicitações. Dentro do critério ABC, Burity (2011) estabeleceu níveis de serviços diferenciados para a classificação ABC, por exemplo: 99\% para itens A, 95\% para itens B e $85 \%$ para itens C, de forma a reduzir o capital empregado em estoques, ou podem-se usar métodos diferentes para controlar o estoque e, assim, minimizar o esforço total de gestão. Este estudo corrobora o nível de serviço diferenciado por classe $\mathrm{ABC}$ encontrado neste estudo, mesmo que este nível tenha seja inferior.

Já no que tange às políticas de ressuprimento, os itens que receberam as classificações $\mathrm{A}$ e X do estoque são aqueles que apresentam maior peso sobre os custos totais e volume consumido. Logo, dentre as políticas de ressuprimento estudadas, a mais indicada para os itens dessa classe é de revisão contínua, pois com as constantes mudanças nos processos e equipamentos, novas necessidades aparecerão e demandas existentes, tendem a diminuir, ou até deixar de existir. Desta forma, será preciso realizar um novo cálculo dos PR's destes itens, de forma a evitar novas ocorrências de falta.

O Estoque de Segurança foi fornecido pela Empresa, e a partir dos dados de lead time de entrega e consumo, conforme Equação 4 e um extrato destes dados com os pontos de ressuprimento que foram recalculados e são apresentados no Quadro 1.

\begin{tabular}{|c|c|c|c|c|c|c|c|c|}
\hline Material & $\begin{array}{l}\text { Quantidade } \\
\text { Consumid? }\end{array}$ & $\begin{array}{c}\text { ABC por valor } \\
\text { consumido no }\end{array}$ & $\begin{array}{c}\mathrm{XYZ} \\
\text { (quantidade }\end{array}$ & $\begin{array}{l}\text { Demanda } \\
\text { Reprimid }\end{array}$ & $\begin{array}{l}\text { Lead Time } \\
\text { (em dias) }\end{array}$ & $\begin{array}{l}\text { Lead Time } \\
\text { (anual) }\end{array}$ & ES & $\begin{array}{c}\text { PR } \\
\text { Propos }^{\text {tn }}\end{array}$ \\
\hline$\checkmark$ & - & ano $\vec{\nabla}$ & consumide $\sqrt{\nabla}$ & & (Crin uias & (alluals & $\checkmark$ & $\begin{array}{r}4 \\
\end{array}$ \\
\hline 1 & 125550 & $\mathrm{~A}$ & $\mathrm{X}$ & 3000 & 41 & 0,11 & 6620 & 20723 \\
\hline 2 & 43884 & $\mathrm{~A}$ & $\mathrm{X}$ & 669 & 49 & 0,13 & 1740 & 7631 \\
\hline 3 & 43400 & $\mathrm{~A}$ & $\mathrm{X}$ & 200 & 28 & 0,08 & 1800 & 5129 \\
\hline 4 & 23200 & $\mathrm{~A}$ & $\mathrm{X}$ & 200 & 27 & 0,07 & 1200 & 2916 \\
\hline 5 & 22515 & $\mathrm{~A}$ & $\mathrm{X}$ & 86 & 38 & 0,10 & 190 & 2534 \\
\hline 6 & 22014 & $\mathrm{~A}$ & $\mathrm{X}$ & 600 & 25 & 0,07 & 1400 & 2908 \\
\hline 7 & 20000 & $\mathrm{~A}$ & $\mathrm{X}$ & 600 & 30 & 0,08 & 1400 & 3044 \\
\hline 8 & 19750 & $\mathrm{~A}$ & $\mathrm{X}$ & 100 & 25 & 0,07 & 1450 & 2803 \\
\hline 9 & 18400 & $\mathrm{~A}$ & $\mathrm{X}$ & 200 & 28 & 0,08 & 1000 & 2412 \\
\hline 10 & 16790 & $\mathrm{~A}$ & $\mathrm{X}$ & 38 & 31 & 0,08 & 838 & 2264 \\
\hline 11 & 16785 & $\bar{A}$ & $\mathrm{X}$ & 23 & 44 & 0,12 & 1500 & 3523 \\
\hline 12 & 16078 & $\mathrm{~A}$ & $\mathrm{X}$ & 20 & 36 & 0,10 & 1038 & 2624 \\
\hline 13 & 14800 & $\mathrm{~A}$ & $\mathrm{X}$ & 200 & 27 & 0,07 & 1200 & 2295 \\
\hline 14 & 14448 & $\mathrm{~A}$ & $X$ & 2 & 39 & 0,11 & 539 & 2083 \\
\hline 15 & 13484 & $\bar{A}$ & $X$ & 500 & 36 & 0,10 & 1400 & 2730 \\
\hline$\vdots$ & $\vdots$ & $\vdots$ & $\vdots$ & $\vdots$ & : & $\vdots$ & $\vdots$ & $\vdots$ \\
\hline $\mathrm{n}$ & $\mathrm{n}$ & $n$ & $\mathrm{n}$ & $\mathrm{n}$ & $\mathrm{n}$ & $\mathrm{n}$ & $\mathrm{n}$ & $\mathrm{n}$ \\
\hline
\end{tabular}


Estes pontos de ressuprimento foram calculados com base nos dados do período de avaliação (outubro de 2012 a setembro de 2013). No entanto, esses valores precisam ser avaliados constantemente, pois cada compra desnecessária ou cada item faltante em estoque pode trazer prejuízos significativos. Por isso, o modelo de política recomendado para este grupo de materiais (itens MRO classificados como A e X), é a política de revisão contínua (s,nQ), onde a demanda e o lead time são variáveis aleatórias, o que pode levar a diferentes modelos e decisões.

Os itens que foram classificados como BY, BZ, CY e CZ, também tiveram seus pontos de ressuprimento recalculados (ver Quadro 2). No entanto, por apresentarem importância inferior do ponto de vista financeiro e também de consumo, pode-se utilizar uma política de ressuprimento de revisão periódica $(\mathrm{R}, \mathrm{S})$, onde a cada $\mathrm{R}$ período de revisão os níveis de estoque são revistos e um pedido é colocado para aumentar a posição de estoque para o nível de $\mathrm{S}$ unidades, ou seja, os níveis de PR serão reavaliados com uma frequência pré-definida pelos gestores de acordo com a estratégia da Empresa.

Quadro 2 - Extrato da lista dos itens B, C, Y e Z com os PR's propostos

\begin{tabular}{|c|c|c|c|c|c|c|c|c|c|}
\hline \multirow[t]{2}{*}{ Material } & \multirow{2}{*}{$\begin{array}{l}\text { Quantidade } \\
\text { Consumid? }\end{array}$} & $\begin{array}{c}\text { ABC por valor } \\
\text { consumido no }\end{array}$ & \multirow{2}{*}{$\begin{array}{c}\mathrm{XYZ} \\
\text { (quantidade } \\
\text { consumide } \sqrt{\square}\end{array}$} & \multirow{2}{*}{$\begin{array}{l}\text { Demanda } \\
\text { Reprimido }\end{array}$} & \multirow{2}{*}{$\begin{array}{l}\text { Lead Time } \\
(\text { em dias }\end{array}$} & $\begin{array}{l}\text { Lead Time } \\
\text { (anual) }\end{array}$ & \multirow[t]{2}{*}{ ES } & \multicolumn{2}{|r|}{$\begin{array}{c}\text { PR } \\
\text { Propos }^{\text {tr }}\end{array}$} \\
\hline & & ano $\nabla$ & & & & (andal) & & 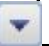 & Propos \\
\hline 1 & 83 & $\mathrm{~B}$ & $\mathrm{Y}$ & 2 & 35 & 0,10 & 10 & & 18 \\
\hline 2 & 79 & $\mathrm{~B}$ & $\mathrm{Y}$ & 7 & 31 & 0,08 & 4 & & 10 \\
\hline 3 & 79 & $\mathrm{C}$ & $\mathrm{Y}$ & 1 & 37 & 0,10 & 5 & & 13 \\
\hline 4 & 79 & $\mathrm{C}$ & $\bar{Y}$ & 7 & 36 & 0,10 & 50 & & 58 \\
\hline 5 & 77 & $\mathrm{C}$ & $\mathrm{Y}$ & 114 & 60 & 0,16 & 2 & & 15 \\
\hline 6 & 8 & $\mathrm{~B}$ & $\bar{Y}$ & 1 & 50 & 0,14 & 1 & & 2 \\
\hline 7 & 8 & $\mathrm{C}$ & $\mathrm{Y}$ & 2 & 49 & 0,13 & 1 & & 2 \\
\hline 8 & 8 & $\mathrm{C}$ & $\bar{Y}$ & 1 & 27 & 0,07 & 4 & & 5 \\
\hline 9 & 8 & $\mathrm{C}$ & $\bar{Y}$ & 1 & 43 & 0,12 & 2 & & 3 \\
\hline 10 & 8 & $\mathrm{C}$ & $\bar{Y}$ & 2 & 140 & 0,38 & 2 & & 5 \\
\hline 11 & 8 & $\mathrm{C}$ & $Z$ & 16 & 35 & 0,10 & 10 & & 11 \\
\hline 12 & 8 & $\mathrm{C}$ & $\bar{Y}$ & 1 & 40 & 0,11 & 1 & & 2 \\
\hline 13 & 7 & $\bar{B}$ & $\mathrm{Z}$ & 1 & 48 & 0,13 & 1 & & 2 \\
\hline 14 & 7 & $B$ & $Z$ & 1 & 50 & 0,14 & 2 & & 3 \\
\hline 15 & 7 & B & $\mathrm{Z}$ & 3 & 73 & 0,20 & 1 & & 2 \\
\hline$\vdots$ & $\vdots$ & $\vdots$ & $\vdots$ & $\vdots$ & $\vdots$ & $\vdots$ & $\vdots$ & & $\vdots$ \\
\hline $\mathrm{n}$ & $\mathrm{n}$ & $\mathrm{n}$ & $\mathrm{n}$ & $n$ & $\mathrm{n}$ & $n$ & $\mathrm{n}$ & & $\mathrm{n}$ \\
\hline
\end{tabular}

Fonte: Autoria própria (2014)

Para simplificação do entendimento e resumo das informações, foi elaborado um quadro síntese com as políticas a serem adotadas para cada classificação de material, conforme pode ser visto no Quadro 3. 
Quadro 3 - Quadro síntese das políticas de ressuprimento de acordo com as classificações

\begin{tabular}{|c|c|c|c|}
\hline Classificação & X & Y & Z \\
\hline A & $\begin{array}{c}\text { Politica de Revisão } \\
\text { Continua (s,nQ) }\end{array}$ & $\begin{array}{c}\text { Politica de Revisão } \\
\text { Continua (s,nQ) }\end{array}$ & $\begin{array}{c}\text { Politica de Revisão } \\
\text { Contínua (s,nQ) }\end{array}$ \\
\hline B & $\begin{array}{c}\text { Politica de Revisão } \\
\text { Continua (s,nQ) }\end{array}$ & $\begin{array}{c}\text { Politica de Revisão } \\
\text { Periódica }(\mathrm{R}, \mathrm{S})\end{array}$ & $\begin{array}{c}\text { Politica de Revisão } \\
\text { Periódica }(\mathrm{R}, \mathrm{S})\end{array}$ \\
\hline C & $\begin{array}{c}\text { Politica de Revisão } \\
\text { Continua (s,nQ) }\end{array}$ & $\begin{array}{c}\text { Politica de Revisão } \\
\text { Periódica }(\mathrm{R}, \mathrm{S})\end{array}$ & $\begin{array}{c}\text { Politica de Revisão } \\
\text { Periódica }(\mathrm{R}, \mathrm{S})\end{array}$ \\
\hline
\end{tabular}

Fonte: Autoria própria (2014)

Cabe ressaltar que todos os itens MRO precisam ser geridos pela empresa, independente do seu valor ou utilização, pois um simples parafuso em falta pode acarretar em uma parada não programada e prejuízos relevantes podem ocorrer. Além do mais, um item que hoje está classificado como item B ou C, em outro momento pode ser A, e vice versa. Da mesma forma, com a classificação XYZ, um item que no momento é utilizado em grande volume, pode deixar de ser demanda em breve. O que se mostrou nesse trabalho que os esforços principais devem ser direcionados aos itens de maior impacto no processo, mas não se deve deixar, sob hipótese alguma, de avaliar constantemente o estoque como um todo.

\section{Considerações finais}

Os estoques de itens de MRO, ao contrário de produtos acabados ou insumos do processo produtivo são itens cuja demanda possui um padrão irregular e intermitente. Portanto, é difícil prever a necessidade quando coexistem itens de baixíssimo giro (que não foram movimentados no período de análise), outros que são movimentados diariamente e em alto volume, e ainda existem peças que valorizam o estoque de forma considerável pelo seu alto custo de aquisição e outros com valores extremamente baixos.

As empresas estão em constante mudança, juntamente com seus processos, equipamentos e materiais utilizados. Logo, a demanda por certos itens podem se alterar com o tempo. Analisar periodicamente os PR's dos materiais pode evitar uma compra desnecessária, contribuindo inclusive, para a redução do excesso de estoque. Por outro lado, caso a demanda tenha aumentado, revisar o ponto ideal de ressuprimento reduz a probabilidade de falta e possibilita uma compra de um lote maior, onde há a possibilidade de se receber um desconto pela compra, além da redução nos custos com transportes de um novo pedido. Com os pontos de ressuprimento defasados, a Empresa faz aquisições desnecessárias, elevando o capital de giro da empresa sem necessidade. A consequência é um alto custo de estocagem que, muitas vezes, se deve a um material que pode, inclusive, se deteriorar, acarretando em um prejuízo que poderia ser evitado. Por outro lado, se o PR estiver baixo, a empresa pode ter seu custo de pedido elevado, já que a quantidade recebida é 
insuficiente para atender à demanda e um novo pedido deverá ser realizado em um tempo inferior ao programado.

Um passo fundamental para a obtenção dos resultados obtidos com este trabalho foi a classificação dos materiais em estoques para posterior análise das decisões por classe. A curva ABC e classificação XYZ constituem ferramentas importantes para priorizar esforços gerenciais e definir os parâmetros no controle dos estoques.

A recomendação de utilização de duas políticas de ressuprimento diferentes deve-se ao fato de que estes itens (MRO) não se assemelham no comportamento, e assim, precisam de tratamentos diferentes. Na política (s,nQ) recomendada para os itens classificados como A e X, é utilizada a posição de estoque e não o estoque líquido para disparar um pedido. A razão é o fato de a posição de estoque incluir os pedidos de materiais que ainda não foram entregues pelo fornecedor.

Com a realização deste estudo, foi possível identificar alguns fatores que influenciam de forma direta na gestão de estoque MRO, tais como a criticidade de operação, os altos custos dos materiais, a distância geográfica dos principais fornecedores, elevados lead time, entre outros.

Considerando a literatura escassa abordando o grupo de materiais MRO, considerando a criticidade operacional destes itens que estão presentes principalmente, nas empresas de transformação, e considerando ainda a complexidade no gerenciamento do estoque desse grupo de materiais, ressalta-se a contribuição que a realização deste trabalho proporciona para os estudos futuros na área de gerenciamento dos estoques.

Por fim, os estudos de aplicação de políticas de controle de estoque nas empresas, em que as questões de diversidade de comportamento da demanda, complexidades, estratégias e esforços gerenciais tornam-se evidentes, contribuem para a redução das lacunas entre a teoria e a prática, ratificando que os avanços conquistados pela teoria acadêmica podem ser aplicados em beneııio do desempenho de organizações no ambiente prático e competitivo.

\section{Abstract}

Stocks are important because of its function to balance the difference between the rates of supply and demand, and to absorb a significant part of any organization's budget. Among the various types of stock, the items MRO - Maintenance, Repair and Operations - involves critical materials, which may have high stock cost, but their lack strongly impacts the financial performance of the company, since it may be essential for certain process or operation, in addition to having a seasonal character. Therefore, the aim of this study is to verify the effectiveness of techniques for determining points of resupply of stocks for the replacement of MRO items through a case study. The Curve ABC and XYZ Classification were used to classify the different materials in stock so that efforts are directed to the most significant items. The results show that different replenishment politics can be adopted according to the needs raised to achieve gains in operational excellence. It is expected that this study can help in decision making in managing stock of MRO items, considering the complexity and peculiarity of this material group.

Keywords: stock management; mro items; resupply point. 


\section{Referências}

ANTUNES J. et al. Sistemas de produção: Conceitos e práticas para projeto e gestão da produção enxuta. Porto Alegre: Bookman, 2008.

AHMED, S; HASSAN, M. H; TAHA, Z. TPM Can Go Beyond Maintenance: Excerpt From a Case Implementation. Journal of Quality in Maintenance Engineering, v. 11, n.1, p. 19-42, 2005. crossref

BALLOU, R. H. Gerenciamento da cadeia de suprimentos/logística empresarial. 5. ed. Porto Alegre: Bookman, 2006.

BETTS, A. et al. Gerenciamento de Operações e de Processos: Princípios e Práticas de Impacto Estratégico. Porto Alegre: Bookman, 2008.

BITTENCOURT, R. Explorar as Possibilidades de Utilização dos Resultados do QFD na Metodologia de Trabalho para a Gestão da Cadeia de Suprimentos: O impacto na gestão dos estoques. Dissertação de Mestrado em Administração. Fundação Getúlio Vargas. São Paulo: FGV, 2006.

BOTTER, R.; FORTUIN, L. Stocking strategy for service parts - a case study. International Journal of Operations and Production Management, v. 20, n. 6, 2000. cross ref

BRIOZO, R. A. Gestão de estoques com Curva ABC: Um estudo de caso no agronegócio brasileiro. Universidade de São Paulo. São Paulo, 2011.

BURITY, M. J. da C. A importância da Tecnologia da Informação (TI) na gestão da cadeia de suprimentos. Rio de Janeiro. 2011.

CARDOZO; L.; CITTADIN; A.; RITTA; C. O;. Modelos quantitativos aplicados à gestão de estoques: Um estudo em uma empresa atacadista de materiais de construção. UFSC. Santa Catarina, 2011.

CORRÊA, H. L.; CORRÊA, C. A. Administração de Produção e Operações. Manufatura e serviços: uma abordagem estratégica. 2. ed. São Paulo: Atlas, 2008.

CORRÊA, H. L. Planejamento, Programação e Controle da Produção. 5. ed. São Paulo: Atlas, 2006.

FIESP. Indicador de desempenho de infraestrutura da Fiesp compara Brasil a principais regiões metropolitanas do mundo. São Paulo, 2013. Disponível em: < http://www.fiesp.com.br/noticias/desempenho-logistico-do-brasil-e-67defasado-a-melhor-infraestrutura-do-mundo-mostra-estudo-da-fiesp/>. Acesso em: 11 jul. 2013.

FRANCISCHINI, P. Administração de materiais e do patrimônio. São Paulo: Pioneira, 2002.

GARCIA, E. S. et al; Gestão de Estoques: Otimizando a Logística e a Cadeia de Suprimentos. Rio de Janeiro: EPapers Serviços Editoriais, 2006.

JURAN, J. M. Planejando para a qualidade. $3^{\circ}$ ed. São Paulo: Pioneira, 1995.

KENNEDY, W.; PATTERSON, J.; FREDENDALL, L. An overview of recent literature on spare parts inventories. International Journal of Production Economics, v. 76, p. 201-215, 2002. crossref

KOCH, R. O Princípio 80/20. Rio de Janeiro: Sextante, 2000.

LARA, M.; RODRIGUES, C. Descrição para a criação da área de planejamento de estoques de peças MRO. Revista Tecnologística, p.82-88, Março, 2012.

LOPES, P. H. M.; SANTOS, W. E. D.; Considerações sobre tributos e estoques na modelagem de redes logísticas. Rio de Janeiro: UFRJ, 2006.

LOURENÇO, K. G.; CASTILHO, V. Determinação da importância operacional dos materiais de enfermagem segunda a classificação XYZ. Revista do Instituto de Ciência da Saúde, v. 27, 2009.

NOGUEIRA, A. Logística Empresarial: Uma visão local com pensamento globalizado. São Paulo: Atlas, 2012. 
OLIVEIRA, V. M. de. Gestão de Estoque MRO em uma Fábrica de Rolamentos. São Paulo, 2013. Disponível em: http://pro.poli.usp.br/wp-content/uploads/2013/10/TF-Victor-Oliveira-VF.pdf. Acesso em: 25 jan. 2014.

PANZUTO, N. S.; RODRIGUES, P. C. C.; Um estudo de caso sobre a gestão de estoques em uma pequena empresa. In: XXX ENCONTRO NACIONAL DE ENGENHARIA DE PRODUÇÃO. São Carlos, 2010.

PINTO, C. V. Organização e Gestão da Manutenção. 2. ed. Lisboa: Edições Monitor, 2002.

PORRAS, E.; DEKKER, R. An inventory control system for spare parts at a refinery: an empirical comparison of different re-order point methods. European Journal of Operational Research, 2008. crossref

POZO, H. Administração de Recursos Materiais e Patrimoniais. 6. ed. São Paulo: Atlas, 2010.

REGO, J. R.; MESQUITA, M. A. Controle de estoque de peças de reposição em local único: uma revisão da literatura. Produção, v. 21, n. 4, p. 645-666, 2011. cross ref

SAGGIORO, E.; MARTIN, A.; LARA, M. Gestão de estoques MRO: otimizando a logística de peças de reposição. Revista Mundo Logística. São Paulo, v.1, n.04, p. 6-10, 2008.

SCHÖNSLEBEN, P. Integral logistics management: operations and supply chain management in comprehensive value added networks. 3. ed. Boca Raton, Florida, USA: Auerbach Publications, 2007. crossref

SLACK, N.; CHAMBERS, S.; JOHNSTON, R. Administração da Produção. São Paulo: Editora Atlas, 2009.

SILVA, G. L. C. Modelo de Estoque para Peças de Reposição Sujeitas à Demanda Intermitente e Lead Time Estocástico. Dissertação de Mestrado em Engenharia de Produção. Universidade Federal de Minas Gerais, Belo Horizonte: UFMG, 2009.

SILVA, L. S. Nível de serviço logístico: estudo de caso de uma empresa de bebidas da Paraíba. XXVIII Encontro Nacional de Engenharia de Produção. UFRGS: 2008.

TADEU, H. F. B. (Org.). Gestão de Estoques: Fundamentos, Modelos Matemáticos e Melhores práticas. São Paulo: Cengage Learning, 2010.

TERSINE, R. J. - Principles of inventory and materials management. Nova Iorque: Elsevier Science Publishing Co., 1988.

TUBINO, D. F. Manual de planejamento e controle da produção. 2. ed. São Paulo: Atlas, 2000.

VENDRAME, F. C. Administração de Recursos Materiais e Patrimoniais. Apostila da Disciplina de Administração, Faculdades Salesianas de Lins. São Paulo: 2008.

WANKE, P. Metodologia para gestão de estoques de peças de reposição: um estudo de caso em empresa brasileira. Rio de Janeiro: UFRJ, 2005.

\section{Dados dos autores}

Nome completo: Bárbara Batista Póvoa

Filiação institucional: Universidade Federal do Espírito Santo - UFES

Função ou cargo ocupado: Aluna

Endereço completo para correspondência: Av. Pico da Bandeira, 1293 - Bairro Água Verde, CEP 36979-000 - Alto Caparaó, MG.

Fone: (27) 99724-2469

e-mail:barbara_povoa@hotmail.com 
Nome completo: Gisele de Lorena Diniz Chaves

Filiação institucional: Universidade Federal do Espírito Santo - UFES

Função ou cargo ocupado: Professora

Endereço completo para correspondência: Rodovia BR 101 Norte, Km. 60, Bairro Litorâneo, CEP 29932-540, São Mateus - ES

Fone: (27) 3312-1572

e-mail: giselechaves@ceunes.ufes.br

Submetido em: 19/03/2014

Aceito em: 17/12/2014 